\title{
UN PROYECTO DE INVESTIGACIÓN ARQUEOLÓGICA EN CÓRDOBA: "PROTOHISTORIA Y ROMANIZACIÓN EN LA SUBBÉTICA CORDOBESA"
}

\author{
Fernando QUESADA SANZ \\ Desiderio VAQUERIZO GIL
}

Introducción: un poco de Historia

La finalidad de este artículo es dar a conocer algunos aspectos de nuestro Proyecto de Investigación Protohistoria y Romanización en la Subbética Cordobesa. Las cuencas de los ríos Almedinilla, Zagrilla y Salado (Depresión Priego-Alcaudete), aprobado y subvencionado por la Consejería de Cultura de la Junta de Andalucía. Para ello, describiremos la fundamentación y algunos presupuestos teóricos de dicho proyecto, sus objetivos, las fases de desarrollo previstas y un resumen de las actividades llevadas a cabo hasta el momento. Puesto que el periodo ibérico es el eje sobre el que se orienta el conjunto de nuestra investigación, centraremos en él nuestros comentarios aunque sin olvidar los antecedentes y momentos posteriores, que serán estudiados con mayor detalle en otros trabajos de éste mismo volumen.

Un grupo cada vez más extendido de investigadores jóvenes ha insistido durante los últimos años en la importancia de los aspectos teóricos en la Arqueología (para un resumen sumamente legible, VICENT GARCÍA, 1983).

"Desde la década de los cincuenta la Arqueología se ha visto obligada a revisar sus postulados fundamentales ante la exigencia de buscar, no sólo métodos más precisos de investigación, sino una teoría que sustentara su objetivo de trabajo sobre bases menos descriptivas y positivistas. Ha sido de este modo como han surgido en los últimos años diversas corrientes cuyo principio básico común valora una arqueología estructural, es decir, un análisis de los elementos arqueológicos en sus diversas relaciones, espaciales, funcionales, cronológicas..." (RUIZ RODRÍGUEZ y MOLINOS, 1984a:421).

"... empieza a apreciarse un sentimiento creciente de que son los presupuestos teóricos los que deben regir toda investigación empírica..." (RUIZ RODRIGUEZ, CHAPA, RUIZ ZAPATERO, 1988:16).

Muchos de estos autores coinciden también en que una de las mayores amenazas a que se enfrenta la Arqueología española en estos momentos es la coexistencia de un arsenal técnico fuerte y desarrollado -técnicas de excavación perfeccionadas, métodos informatizados de registro y acceso a los datos, métodos isotópicos de datación, análisis polínicos, 
etc...- con una notable debilidad del marco teórico en que se sustenta nuestra disciplina (RUIZ, MOLINOS, HORNOS, 1986:47; MARTINEZNAVARRETE 1989:71), sin el cual se corre el peligro de que la masa de información trabajosamente obtenida y registrada sea en el fondo inútil.

Para estos arqueólogos es preferible contar con un marco teórico explícito y definido -aunque no sea el que ellos mismos sustenten- antes que ver a otros autores lanzados a un trabajo de campo sin una base teórica explicitada. Al menos, argumentan, se podrá entablar así una discusión científica centrando el debate de manera provechosa. Esta es, por ejemplo, la postura adoptada por RUIZ RODRÍGUEZ, CHAPA y RUIZ ZAPATERO (1988:16) al realizar una dura crítica de la base teórica de la llamada "arqueología contextual":

"La diferencia mayor está en que la escuela contextual se ha esforzado en exponer repetidamente sus creencias y formas de trabajo, mientras que la investigación peninsular sigue siendo hermética en cuanto a tos principios que la rigen. Por ello, nunca se insistirá bastante en la necesidad de que toda investigación busque un marco teórico coherente, sea el que sea, puesto que sólo así podrá constituirse un debate en el que se: clarifiquen las posturas, y con ellas, los procedimientos de trabajo."

La utilización de técnicas perfeccionadas de trabajo sin base teórica clara no supone para estos autores un verdadero y decisivo avance en nuestros conocimientos, sino a lo sumo una acumulación de información procesada pero no realmente digerida y utilizable.

Otros grupos de investigadores, por lo general ligados a escuelas más tradicionales y menos comprometidas ideológicamente -o al menos no de forma declarada- mantienen un empirismo independiente de la teoría, enfocando su interés hacia la elaboración de tipologías y cuadros cronológicos, centrados en el nivel de "objeto" o "vestigio", cuando no en aspectos estéticos, pero sin introducirse en aspectos más ligados a la Antropología Cultural. Evidentemente menos propensos a expresar por escrito sus posturas "teóricas", tienden a considerar cuando menos farragosa la precipitada sucesión de "ismos" adoptado; como última novedad por los "arqueólogos comprometidos", así como la terminología por ellos empleada. En casos más extremos, rechazan radicalmente la noción de que una Teoría explícita deba sustentar la investigación arqueológica: desde su punto de vista, esta base teórica supone un corsé que en casos leves actúa como orejeras y en casos extremos puede llevara forzar los datos para adecuarlos a una Teoría previa. Teoría que muchas veces hunde sus raíces en convicciones personales profundas que ' 'contaminan" la necesaria "objetividad" del investigador, objetividad que es negada por otros autores (V1CENT, 1983:63).

Algunos de los investigadores de esta corriente -que en realidad no existe como tal- están adoptando procedimientos y técnicas ligados a las distintas tendencias agrupadas por su interés en la Teoría, pero sin adoptar su énfasis en la misma. Estos son para los autores del primer grupo los casos más peligrosos, pues encubren con un barniz de "cientifismo tecnicista" una carencia de Metodología en el más amplio sentido de la palabra y un reforzamiento de la orientación tradicional (MARTÍNEZ NAVARRETE, 1989:70).

No vamos a caer en las páginas que siguen en el error de mezclar procedimientos y teoría, ni confundiremos "Nueva Arqueología" con la incorporación de nuevos procedimientos empíricos, confusión denunciada por autores como M.l. MARTÍNEZ NAVARRETE (1989:6; 39-40; 71). Sólo intentaremos trazar un rápido panorama de las líneas de trabajo y discusión en plena actualidad, y que por acción u omisión influyen en cualquier investigación que se realice. Por tanto, en los párrafos que siguen aparecerán -juntos pero 
no revueltos- ambos aspectos. No se trata, aquí y ahora, de hacer Teoría, sino una breve Historia de la Investigación para dar idea del marco teórico general en que se encuadra nuestro Proyecto, tocando temas que de una manera u otra influyen directamente en los planteamientos actuales de la Arqueología Protohistórica andaluza.

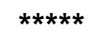

Un punto conveniente para comenzar nuestra exposición es el año 1975, cuando J. ALONA publicó un trabajo en el que comparaba la Arqueología española de ese momento con la americana de los años cuarenta en lo referente al desarrollo de la Teoría. Americanista que desarrollaba su trabajo en el Dpto. de Antropología y Etnología Americanas, sus contactos en América le permitieron superar la perspectiva tradicional; ya entonces planteaba muchos de los temas en pleno debate actual. Desde su punto de vista las principales características de la Arqueología española de entonces eran (ALCINA, 1975:68) a) Carencia teórica casi absoluta; b) Carencia de programa; c) Nivel descriptivo ("arqueográfico") generalizado; d) Nivel interpretativo exclusivamente historicista; e) Déficit en el estudio del componente ambiental; f) Ausencia de estudios multidisciplinares. Estas son, en esencia, las críticas que todavía se hacen a buena parte de la Arqueología hispana desde las posiciones más progresivas.

Desde los años setenta, sin embargo, se produce una cada vez más intensa y acelerada entrada en España de los conceptos de la Arqueología Anglosajona y en especial americana, que en muchos ámbitos va desplazando a la corriente tipológico-cronológica clásica, fuertemente enraizada en las escuelas francesa y alemana, modelos de la española durante la primera mitad del siglo. Las razones de esta alteración son múltiples y entre ellas se cuenta, por banal que parezca, el cambio de énfasis en la enseñanza de idiomas extranjeros en nuestra enseñanza: en un país donde el conocimiento de idiomas entre estudiantes universitarios ha sido tradicionalmente paupérrimo, el cambio de énfasis del francés al inglés en los estudios medios por razones en todo ajenas a la Arqueología, ha facilitado a toda una generación de licenciados universitarios el acceso a trabajos anglosajones, habida cuenta de la escasez de traducciones (vid. infra).

El proceso de desarrollo teórico apreciado en los países anglosajones desde la década de los sesenta llegó a España con considerable retraso en la segunda mitad de los setenta, primero aisladamente, pero desde comienzos de los ochenta en forma torrencial y arrolladora, provocando, con el agolpamiento apresurado de las nuevas ideas y métodos, una cierta confusión de "ismos" y de procedimientos de trabajo que ha hecho retroceder a muchos, amparados en la aparente o real contradicción entre muchas de esas tendencias. (RUIZ, MOLINOS, HORNOS, 1986:40-48; FERNANDEZ MIRANDA, 1988; CHAPA BRUNET, 1988; RUIZ RODRÍGUEZ, CHAPA, RUIZ ZAPATERO, 1988; MARTÍNEZ NAVARRETE 1989:57-120; FERNANDEZ MARTÍNEZ, 1989:225-268). Salvo en el caso de algunos "adelantados", en muchos grupos de arqueólogos hispanos -por lo general carentes de una formación sistemática en Filosofía de la Ciencia y no demasiado interesados en el debate ideológico- no ha existido tiempo material para diseccionar y digerir esta avalancha. De todas formas, una prueba del escaso impacto que en un principio tuvieron las nuevas ideas es que. como ha señalado recientemente RUIZ ZAPATERO (1987:318). los libros básicos de la "New Archaeology" no llamaron la atención de ningún recensionista en las principales revistas especializadas españolas.

Una de las formas posibles de calibrar el aumento del interés por los nuevos métodos y 
sistemas de la Arqueología es estudiar las traducciones realizadas de trabajos de estas tendencias, así como el desfase entre su publicación original y la edición en español (aunque lógicamente esto refleja el creciente interés sobre la Arqueología en general).

De nuevo resulta pionera la actitud del Departamento de Antropología y Etnología americana de la Universidad Complutense, que en sus Cuadernos de Antropología Social y Etnología dedicó amplio espacio a la traducción de artículos de autores anglosajones, lo que por otra pane da una idea del triste panorama hispano. En los primeros setenta, y gracias sobre todo al esfuerzo de investigadores individuales como Miguel Rivera Dorado, una editorial de gran difusión traduce con desfase temporal relativamente amplio ( 9 y 3 años respectivamente), las obras de CHANG (1976) y WATSON, LeBLANC y REDMAN (1974), estos últimos máximos exponentes del hoy desacreditado grupo "ley y orden". A partir de estos comienzos vacilantes, el ritmo de traducciones durante los setenta fue aumentando, aunque todavía con grandes desfases cronológicos: la Introducción a la Arqueología Prehistórica de HOLE y HEIZER (1977), 12 años; la Arqueología y Sociedad. de Clark (1980), 41 años; el volumen de Ciencia en Arqueología (BROTH WELL y HIGGS: 1980), 17 años. Desde comienzo de los años ochenta el ritmo de traducciones se incrementó, reduciéndose progresivamente los desfases, aunque se mantuvieron durante varios años algunas significativas omisiones de obras fundamentales. Así, se tradujeron la Arqueología Analítica (CLARKE, 1984), (16 años aunque sólo 6 desde la segunda edición revisada); $E l$ Alba de la Civilización de Renfrew (1986), (13 años); Desenterrando Huesos (BROTHWELL, 1987), (5 años); Matemáticas para Arqueólogos (ORTON, 1988), (8 años); En Busca del Pasado (BINFORD, 1988), (5 años); Interpretación en Arqueología (HODDER, 1988), (2 años).

Durante bastante tiempo, toda la bibliografía disponible sobre las nuevas tendencias teóricas y sobre los nuevos procedimientos de trabajo llevaba firmas anglosajonas. Sólo desde principios de los ochenta -y salvo excepciones como las antes reseñadas- comenzaron a publicarse estudios españoles e incluso trabajos críticos con dichas tendencias desde posturas teóricamente explícitas. Un punto de inflexión bastante definido lo constituye en 1981 la celebración en Soria, con apoyo oficial, de las "Primeras Jornadas de Metodología de Investigación Prehistórica". Se presentaron entonces, por parte de investigadores españoles, un número relativamente reducido pero ya significativo de trabajos que tocaban lemas de Epistemología, Tipología, Informática, Arqueología espacial, etc., juntos pero, según decíamos antes, no revueltos. Aún así, estos trabajos pioneros debían remitirse a bibliografía casi en exclusiva foránea: FERNANDEZ MIRANDA (1984:20) citaba 8 trabajos extranjeros sobre un total de 8 títulos; ESTEVEZ et al. (1984:21-31), 9 sobre 10; MARTIN DE GUZMAN (1984:61-64) 126 sobre 132; CERRILLO MARTIN DE CACERES (1984:69), 10 sobre 10; VICENT (1984:87), 21 sobre 23; BURILLO (1984:431-441), 18 sobre 24.

Es sólo desde principios de los ochenta cuando comienzan a publicarse en número creciente artículos de autores españoles relacionados con las dos ramas de las nuevas tendencias, las centradas en aspectos teóricos y las que aprovechan los nuevos procedimientos de trabajo que, en tos países anglosajones, van indisolublemente unidos a un fuerte componente teorético. Se van produciendo "declaraciones de principios" explícitas, como la precursora de A, RU1Z en "Los pueblos iberos del Alto Guadalquivir" (1978), o la aún más influyente de V. Lull (1983), cuyo trabajo trasciende lo concreto del tema para ser de aplicación general, como el propio subtítulo del libro indica ("Un modelo para el estudio 
de las formaciones económico-sociales prehistóricas"). En ambos trabajos, la base teórica marxista y el método del materialismo histórico son explícitos,

Quizá no sea extraño que muchas de las propuestas innovadoras mejor organizadas y a mayor escala hayan nacido en centros universitarios jóvenes y periféricos, como los Colegios Universitarios de Teruel y Jaén. Por lo que se refiere al primero, y bajo el impulso y coordinación de F. Burillo (quien ya en 1980 publicó un excelente trabajo en el que prestaba enorme atención a la relación de los asentamientos entre sí y con su medio circundante, BURILLO, 1980), se convocó en 1984 el primer "Coloquio de Arqueología Espacial", que tuvo un resonante éxito de asistencia y organización (las Actas estuvieron publicadas antes de celebrarse las sesiones de trabajo), aunque la calidad de los trabajos presentados fuera todavía desigual. Los coloquios de "Arqueología Espacial" se han seguido celebrando con temas más concretos (Microespacio en 1986; Fronteras en 1989), y su éxito certifica la extrada "en tromba" de la Arqueología Espacial como base teórica más o menos explícita y como procedimiento de trabajo para muchos arqueólogos españoles.

No solamente en cuestiones como la Arqueología Espacial suponen un gran salto los años ochenta. También en estas fechas comienzan a ser frecuentes los trabajos de carácter teórico, como los de J.M. Vicent García o E. Cerrillo Martín de Cáceres. Más aún, estos trabajos no se limitan al ámbito del artículo especializado, sino que saltan a ámbitos de difusión mayor. Así podemos citar, ya muy reciente, la densa síntesis realizada en la primera parte del libro de M. Isabel Martínez Navarrete (1989), que ha merecido una reseña en un periódico de difusión nacional (ABC, 6 Enero 1990). Dicha actitud, que aúna la preocupación teórica con la utilización de medios sofisticados de análisis se ha trasladado también al campo de la recensión de trabajos arqueológicos (RUIZ ZAPATERO, 1989:331-340). Del mismo modo, no se acepta tal cual todo "lo que viene de fuera", y se someten las nuevas corrientes teóricas a una reflexión crítica intensa (RUIZ RODRÍGUEZ, CHAPA, RUIZ ZAPATERO, 1988). En un círculo aún más amplio, aparecen ya manuales de Arqueología destinados a los estudiantes de primeros cursos de Universidad que recogen con cierto detalle los problemas teóricos y no sólo los procedimientos de excavación. Nos referimos al reciente libro de V, FERNANDEZ (1989), cuya comparación con otros manuales "clásicos" todavía utilizados (ALMAGRO, 1960; WHEELER, 1961; RAMOS FERNANDEZ, 1977) resulta especialmente ilustrativa. Por último, y ya dentro de la literatura de ámbito general, no puede ser casualidad que en 1988 la "Revista de Occidente" dedicara su número 81 a "La Arqueología Hoy", incluyendo entre sus artículos una extensa entrevista a Colin Renfrew.

El Colegio Universitario de Jaén ha sido otro de los centros innovadores en el ámbito arqueológico, cuya aportación para el estudio de la Cultura Ibérica en general y andaluza en particular puede ya calificarse de decisiva. Tras un primer artículo premonitorio de A. RUIZ (1978), en las Jornadas de Soria ya citadas de 1981 se publica un trabajo (RUIZ y MOLINOS, 1984a) que contiene las líneas esenciales de un Proyecto de Investigación a gran escala que todavía continúa. Ya se aprecia en él un fuerte interés en la teoría, la base materialista no reduccionista y el recurso a los procedimientos de la Arqueología Espacial para realizar un completo análisis de la ordenación del territorio, superando definitivamente el análisis del objeto e incluso del yacimiento aislado o en relación con su entorno inmediato; todo ello dentro de un marcado interés por las estructuras políticas y por la Historia. No hay que olvidar por otro lado que en el programa de Jaén no sólo entra el mundo 
ibérico, sino que se integran diversas investigaciones referidas a la Edad del Bronce, época romana, etc...).

El primer Coloquio de Arqueología Espacial de Teruel de 1984 recogerá también varios trabajos del grupo de Jaén. Por lo que se refiere al tema y periodo que ahora nos ocupa, conviene recordar la comunicación que continúa en la línea de las ya citadas (RUIZ Y MOLINOS, 1984b), pero sobre todo otra (CHOCLAN, HORNOS, MOLINOS, RUIZ, 1984) que presenta un completo modelo de ficha de campo para la recogida de información en prospecciones. En efecto, este artículo nos sirve para recordar la creciente importancia que para estos grupos de investigaciones (amén de otros que trabajan sobre otros periodos y que aquí no recogemos por mera cuestión de espacio) va adquiriendo la realización de prospecciones de campo, entendidas no en el sentido tradicional como un método para localizar yacimientos "excavables" sino como parte integral, esencial y primordial de cualquier proyecto que tenga en cuenta la relación de la sociedad ibérica con el espacio en que se asienta: como tal relación es inevitable y fundamental, también es imprescindible estudiarla, y un Proyecto que no tenga en cuenta el medio geográfico en todas sus facetas así como las formas de ocupación, explotación y ordenación del territorio carece de sentido e incluso de validez científica.

"Así, la recuperación de la prospección sistemática como base de los estudios sobre la ocupación del espacio (territorio) por las sociedades humanas y de las relaciones entre los asentamientos, ha abierto una nueva línea novedosa no sólo en lo referente a utilización de técnicas distintas, sino fundamentalmente en su contenido teórico y en aspectos metodológicos." (RUIZ, MOLINOS, HORNOS. 1986:47)

(el subrayado es nuestro)

Más adelante, los sucesivos Coloquios de Arqueología espacial han reflejado la labor investigadora del Colegio de Jaén, hasta el punto de que las actividades de ambos Colegios aparecen de alguna manera coordinadas, al menos en la evolución de sus intereses científicos (RUIZ, MOLINOS, NOCETE, CASTRO, 1986; RUIZ Y MOLINOS, 1989; MONTILLA, RISQUEZ, SERRANO y COBA, 1989).

Todo esto va forjando un modelo en el que, por vez primera, prima la prospección sobre la excavación, algo absolutamente inaudito, pero explicable si se tiene en cuenta la utilidad añadida de la prospección como fuente de información para la realización de inventarios, base a su vez de la política de gestión de los recursos disponibles por parte de muchas comunidades autónomas (CASTRO LÓPEZ, 1986:71; MARTÍNEZ NAVARRETE, 1989:119). Si para M. Wheeler Arqueología de campo era prácticamente sinónimo de excavación, y su condición de Ciencia dudosa (WHEELER, 1961:10). en manuales modernos llega a afirmarse que el "surgimiento de corrientes teórico-metodológicas [...] ha colocado en primer plano de importancia a la prospección, por encima incluso de la excavación..." (FERNANDEZ, 1989:46).

Pero los arqueólogos del grupo de Jaén no se han limitado a presentar resultados -hasta ahora parciales- de sus trabajos, sino que, consecuentes con su propio concepto de Ja Investigación, han procedido a explicitar -al menos en parte- sus concepciones teóricas. De ahí que casi todos sus trabajos presenten consideraciones en este sentido, y sobre todo la publicación de un importante librito: Arqueología en Jaén (Reflexiones desde un proyecto arqueológico no inocente) (RUIZ, MOLINOS, HORNOS, 1986) cuyo subtítulo alude al conocido artículo de D.L. Clarke (CLARKE, 1973). En él se plantea una verdadera 
"Declaración de Principios con Programa", incluyendo entre otras cosas una Historia de la Arqueología en Jaén, un capítulo significativamente titulado "Hacia una Arqueología científica y teórica" y un breve estudio de la Legislación vigente para la conservación del Patrimonio. Esta continuidad de trabajos financiados y avalados por la Junta de Andalucía, el esfuerzo por explicitar las posturas teóricas y los resultados hasta ahora presentados, han llevado a algún arqueólogo a considerar entusiásticamente que:

"... la línea de investigación emprendida por el equipo jiennense es la más completa de las que configuran el panorama de la Prehistoria española. Responde a un programa coherente y planificado que aúna los desarrollos teóricos con sus correspondientes articulaciones empíricas en un mismo proceso de conocimiento. Las políticas de investigación y de gestión de recursos culturales se integran en un proyecto expreso de crítica social en el que una vía da sentido a la otra... Los problemas se localizan en e) terreno de) contraste empírico [...] ello [...] es achacable [...) al carácter incompleto del registro arqueológico actualmente disponible o al hecho de que las publicaciones sean sólo avances de programas en curso. [...] A la vista de los resultados obtenidos, cuando existe una adecuada confrontación con el registro arqueológico!...] no parece exagerado suponer que el conocimiento de la "Arqueología de la Historia de Jaén" será uno de los más sólidos de todo el país -si no el más- de aquí a unos pocos años". (MARTÍNEZ NAVARRETE, 1989:99)

Vemos pues que la Arqueología Espacial se ha convertido en uno de los instrumentos básicos para el estudio del mundo ibérico. En este sentido conviene retomar aquí algo de lo que decíamos en los primeros párrafos de este artículo. A. Ruiz ha criticado recientemente (en el curso de verano de la U.A.M, "Arqueología del mundo ibérico", celebrado en Miraflores de la Sierra en julio de 1989) la utilización indiscriminada de métodos de la "Arqueología Espacial" sin tener en cuenta algunos factores: en primer lugar la necesidad de una crítica teórica previa de los conceptos de base ("el problema reside en la toma indiscriminada de modelos de trabajo elaborados por y para otras disciplinas, sin sufrir la criba de la crítica sobre la base teórica que la sustenta y la utilidad que debe tener para la Arqueología"); en segundo lugar, cuestiona (sólo en apariencia sorprendentemente para un materialista histórico) "el reiterado olvido de los factores no económicos, que conducen a un reduccionismo economicista difícil de evitar". Por dirimo realiza A. Ruiz un caveat sobre la necesidad de una calidad adecuada del trabajo de prospección. Estas opiniones no deben entenderse, creemos, como una autocrítica de las limitaciones de la Arqueología Espacial (que las hay), sino como una crítica de la utilización indiscriminada de procedimientos nuevos tomados de la Geografía Locacional Moderna que se refiere a una economía de mercado sin una base teórica explícita.

Junto con el intenso debate teórico y la irrupción de los métodos de la Arqueología Espacial hay otros muchos aspectos cuya incidencia sobre cualquier trabajo arqueológico emprendido recientemente es grande. Entre ellos queremos destacar algunos que en nuestra caso resultan especialmente significativos. En primer lugar no se puede olvidar la eclosión de lo que se ha dado en llamar "Arqueología de la Muerte" (CHAPMAN, KINNES y RANDSBORG, 1981, con numerosa bibliografía; ALEKSHIN, 1983), muy relacionada con el nivel semimicro y micro de la Arqueología Espacial, pero también con una amplia serie de cuestiones entre las que destaca el intenso interés que ha despertado en los últimos años el estudio sistemático de la estructuración social jerarquizada entre los iberos y el de 
la relación entre ritual funerario y prestigio social (QUESADA, 1989a).

En segundo lugar, debe recalcarse también el creciente interés por la mejora de las técnicas de excavación y de recogida de la información (MARTÍNEZ NAVARRETE, 1989:69-70; FERNANDEZ, 1989:63 ss), reflejado también en la traducción de algunos libros sobre técnicas específicas (BROTHWELL, 1987) o la difusión de trabajos como el de HARRÍS (1979), traducido informalmente en algunos centros universitarios e incluso resumido para consumo local (PRIETO VÁZQUEZ, 1987), con la introducción del concepto de contexto como unidad básica de excavación y recogida de información, superando además -en los casos en que es necesario- el sistema de cuadrículas de escaso tamaño para sustituirlo por excavaciones en área, especialmente útiles en yacimientos con estructuras potentes y escasa estratificación vertical.

También es decisivoel creciente interés por la ayuda que puedan prestar a la arqueología otras ciencias (ver por ejemplo las distintas comunicaciones presentadas a las Jornadas sobre Metodología Arqueológica celebradas en Murcia en Septiembre-Octubre de 1986 o la más antigua traducción del libro coordinado por BROTHWELL y HIGGS (1980). Poco a poco se va superando el interés centrado exclusivamente en la datación isotópica o reflejado en la publicación de apéndices con análisis polínicos, paleoantropológicos, antracológicos, edafológicos, etc. para integrar los resultados de todos esos análisis no sólo en el texto del Informe o Memoria, sino en la propia concepción del proyecto de investigación. Los análisis de este tipo se hacen cada vez menos para yuxtaponer un apéndice -cuanto más denso mejor- y más para resolver problemas concretos que requieren de la ayuda de cuantas fuentes de información sea posible, dentro de proyectos verdaderamente multidisciplinares.

Va adquiriendo también importancia la conciencia de que con excavar y publicar un yacimiento no ha acabado la labor de un equipo. Todas las cuestiones centradas en el inventario, restauración, conservación y exhibición al publico del Patrimonio Arqueológico -concebido como Patrimonio de todos- son de interés primordial para las distintas administraciones públicas (PRICE, 1984), que naturalmente tienden a primar trabajos que tengan en cuenta todos estos aspectos (RUIZ, MOLINOS, HORNOS, 1986:49-56). De ahí el auge que la excavación de Urgencia va tomando en la Arqueología Española (FERNANDEZ, 1989:61) y mundial (BARKER, 1977:122 ss.), debido sobre todo al crecimiento exponencial de las obras de carácter público. Como todo ello ha afectado a nuestro proyecto lo veremos más adelante.

Por último, no podemos cenar este apartado sin aludir a todas las técnicas de cuantificación (por ejemplo, ORTON, 1988) que han irrumpido con enorme fuerza en la Prehistoria y posteriormente en la "Arqueología clásica", mediante la utilización de estadísticos cada vez más sofisticados. La cuantificación no es un conjunto aséptico de técnicas, y del concepto de "Tipología" y "clasificación" que se utilice (derivado en último extremo de los planteamientos teóricos personales, sean éstos explícitos o no) se derivarán enfoques diferentes (CONTRERAS, 1984). De la misma manera, hace falta disponer de criterios claros sobre los problemas arqueológicos que se van a abordar antes de comenzar a utilizar la estadística (QUESADA, 1989b; GIMENO, GONZÁLEZ, QUESADA, 1988). Por ejemplo, conviene recordar que la seriación automática de un conjunto no implica necesariamente qua la ordenación resultante sea cronológica (FERNANDEZ, 1985).

La gran cantidad de información que llega a generarse en los estudios arqueológicos modernos, y el tipo de preguntas que se realizan a los materiales ha llevado de manera 
natural a que se utilice la Informática como auxiliar cada vez más imprescindible a la hora de realizar cualquier trabajo. La bibliografía generada en torno a este tema es ya inmensa y no nos entretendremos en ella (GIMENO, GONZÁLEZ, QUESADA, 1988; RICHARDS y RYAN, 1985).

Los innegables avances realizados por la Arqueología española en todos los campos durante las dos ultimas décadas, y en particular el fuerte impulso dado a la investigación arqueológica en la Campiña jiennense por el Colegio Universitario de Jaén -por citarel caso más próximo geográficamente a nosotros- ha puesto en verdad muy alto el listón para cualquier otro Proyecto nacido una década después y con distintos condicionantes y objetivos. En las páginas que siguen trataremos de trazar cuales son las características principales de nuestro propio trabajo, aunque sin entrar aquí-no es el momento- en el ámbito de las consideraciones teóricas.

La génesis de un proyecto de investigación

Independientemente de los planteamientos ideológicos personales de cada investigador -que incluso pueden ser diferentes en distintos miembros de un mismo equipo, enriqueciendo así el debate interno del mismo y la formulación de su Metodología-, es un hecho que junto con la base teórica hay que contar con un cuerpo de información factual sobre la que trabajar. No se trata de excavar o investigar "a ver que nos cuentan las cosas", sino de reconocer la posición de partida, las ventajas y deficiencias de la información disponible y las necesidades materiales de recogida de datos. Siempre, incluso si se quiere avanzar por cualquiera de los planteamientos que hemos recogido en el apartado anterior, es necesario contar con un esqueleto cronológico y tipológico sólido y realizado con criterios actuales (ver LULL, 1983 y CONTRERAS, 1985 para una discusión sobre las nuevas necesidades y métodos en la realización de Tipologías). Esta construcción en cierto modo "clásica" de un esqueleto es esencial para evitar construir grandes formulaciones basadas en cronologías o tipologías rápidamente obsoletas por mal planteadas que no por el lógico avance de la investigación. Como ha indicado T. Chapa (1988:139):

"... aún faltan en nuestra Península secuencias de cultura material bien fechadas y descritas, lo que dificulta cualquier comprobación de los presupuestos teóricos previamente establecidos. Sin embargo, la ausencia de estos últimos deja sin rumbo a la investigación empírica, demasiado compleja y costosa hoy en día como para trabajar sin una orientación firme." (El subrayado es nuestro)

En nuestro caso, los trabajos de excavación en el Cerro de la Cruz -uno de los ejes fundamentales de nuestro proyecto- se originaron por una deficiencia de información factual para un determinado propósito -dotar de un mínimo contexto a una espléndida serie de artefactos depositados en colecciones museísticas-. Con el paso del tiempo, la adquisición de información factual sigue siendo una necesidad imperiosa: a nivel de objeto, para poder construir una inexistente Tipología de material cerámico de Baja Época en esta zona; a nivel micro y semi-micro, para poder confirmar hipótesis sobre la incidencia del mundo romano en el poblado tardío del Cerro de la Cruz, la distribución de espacios públicos/privados, la presencia/ausencia de fortificaciones, etc.; a nivel macro, para contrastar hipótesis sobre el carácter fronterizode la zona (MURILLOet alii, 1989), sobre la dependencia-oposición con 
el cercano Cerro de las Cabezas de Fuente Tójar, sobre el tipo y alcance del control económico y político del territorio circundante a estos dos grandes oppida; sobre la escasez de poblamiento en el Bronce Final, sobre el carácter violento inicial de la Romanización en la zona, etc.

En nuestro proyecto, la realización de prospecciones sistemáticas y la adopción matizada de métodos de la Geografía Locacional para el estudio del poblamiento y la ordenación del territorio desde el Bronce Final al mundo romano son sólo una de las puntas de la investigación. Las otras dos grandes direcciones de trabajo pasan por: a) El estudio a gran escala de la urbanística de un poblado ibérico excepcionalmente bien conservado por la destrucción violenta de una amplia zona -si no de la totalidad-, entendiendo por tal no sólo el análisis de las estructuras físicas, sino también el de todos los materiales en ellas hallados, y sobre todo el de las relaciones sociales y de producción que puedan deducirse de la interacción entre los modelos de trabajo y las modificaciones que el estudio de los restos materiales impongan a los mismos.

b) En segundo lugar, es nuestro propósito continuar la dura -y en muchos sentidos sacrificada- tarea de proteger en lo posible el Patrimonio de la Subbética cordobesa no sólo potenciando la protección, conservación, restauración y eventualmente apertura al público de los yacimientos estudiados de manera sistemática, sino también, y como ha ocurrido con la villa romana del Ruedo, seguir con atención las distintas obras públicas que se realicen y tratar de proteger en la medida de nuestras posibilidades humanas y administrativas los nuevos vestigios que ininterrumpidamente salen a la luz y que a menudo fuerzan a interrumpir el trabajo más o menos sosegado de la investigación sistemática para lanzarse al trabajo frenético del trabajo de urgencia y salvamento.

El origen último de nuestro Proyecto se halla en el trabajo realizado por uno de nosotros como Tesis Doctoral (VAQUERIZO, 1988a), que a su vez deriva de una pesada herencia que se remonta a mediados del siglo pasado. En 1867 L. Maraver y Alfaro, a la sazón conservadordel recién creado Museo Arqueológicode Córdoba (VICENT, 1984-85:34-45) realizó excavaciones en la necrópolis de "Los Collados", $500 \mathrm{~m}$. al Sur del Cerro de la Cruz, que domina la actual Almedinilla por el Suroeste. En dicha excavación halló Maraver 253 sepulturas, que nunca fueron publicadas, a excepción de un breve resumen de los hallazgos (MARAVER, 1867a, 1867b). El gráfico publicado por J. PEREIRA (1988:58) explícita claramente que esta excavación fue la primera realizada sobre un yacimiento ibérico en Andalucía, y la única durante más de treinta años.

Mucho tiempo después, en 1903, excavaron en el propio Cerro de la Cruz P, París y A. Engel (PARÍS y ENGEL, 1906), pero sin realizar una publicación sistemática y completa de los importantes hallazgos. Como resultado de estas excavaciones muy antiguas y del comercio de antigüedades, los materiales se dispersaron por diversos museos (Córdoba, Arqueológico Nacional de Madrid, M. des Antiquités Nationales de París, British Museum, etc.). La Tesis Doctoral a la que hemos aludido se propuso estudiar todos estos materiales dispersos, siempre citados pero nunca concienzudamente analizados y mucho menos publicados. La propia dinámica de los acontecimientos aconsejó realizar una primera campaña de excavación sistemática a escala reducida en 1985, con el objetivo de documentar la secuencia estratigráfica del poblado del Cerro de la Cruz (VAQUERIZO, 1985:319), y también con la intención de detener el masivo y flagrante expolio a que venía siendo sometido incluso con el empleo de máquinas retroexcavadoras, situación denunciada 
públicamente ya desde 1983 (SÁNCHEZ SASTRE, 1983:48-49).

Sólo desde entonces, y como consecuencia de los prometedores resultados de 1985, se planteó la realización de un Proyecto a mayor escala, enfocado en un principio a la excavación en extensión del poblado del Cerro de la Cruz. El tema de investigación -centrado en un yacimiento y su entorno inmediato-, se justificaba por la ausencia de excavaciones en extensión de poblados ibéricos en Andalucía, en especial de Baja Época (datación que los sondeos de 1985 nos proporcionaban para las estructuras del último nivel de ocupación). La excavación de un poblado bien conservado podía proporcionamos datos de enorme importancia en el nivel semimicro, quizá el menos tocado por otras investigaciones sobre el mundo ibérico andaluz (los trabajos del equipo de A. Ruiz se dirigían sobre todo al estudio de relaciones entre asentamientos y control del territorio, y los de T, Chapa y J. Pereira en Castellones de Ceal (CHAPA, PEREIRA, 1986; CHAPA, RUIZ, PEREIRA, 1985) al nivel microespacial, con especial incidencia en la necrópolis). La campaña de 1987 se orientó pues, en este sentido, excavándose un total de 270 metros cuadrados.

Pero la propia dinámica de los acontecimientos (cambio en circunstancias académicas, necesidades de la investigación, incorporación de nuevas personas al equipo de trabajo) facilitó el que en 1989 el Proyecto tomara su configuración actual, ampliando la zona de estudio al conjunto de la Depresión Priego-Alcaudete y por tanto incluyendo el nivel macro; y también ampliando el marco cronológico, para incluir las fases del Bronce Final y la Romanización. Es evidente, por tanto, que el proyecto que ahora llevamos a cabo se distancia mucho en alcance, medios y objetivos de aquella modesta excavación inicial en el Cerro de la Cruz. El planteamiento actual es ya a medio-largo plazo, y sus objetivos sólo podrán cubrirse si se cuenta con el adecuado equipo técnico y con una adecuada financiación acorde con el alcance mucho mayor de las actuaciones previstas.

La Historia del desarrollo de este Proyecto, lejos de presentar un aspecto monolítico y planificado ab initio muestra una realidad mucho más acorde con loque es la situación actual de la Arqueología Cordobesa, y con lo que era en 1985. El Proyecto ha crecido con los medios y el equipo disponible, y lejos de presentarse como una unidad completa y perfectamente prevista y planificada desde su comienzo (circunstancia que en nuestra experiencia muy rara vez se da), quiere reconocer que ha debido ir adaptándose a las circunstancias -por fortuna en constante mejora- hasta su complejo planteamiento actual. Pero antes de entrar a describir con cierto detalle las fases y objetivos del mismo tal y como se plantean a finales de 1989 es preciso hacer un alto para describir la situación general de la Arqueología cordobesa y para precisar geográficamente el área objeto de estudio.

Algunas notas sobre la cultura ibérica y arqueología cordobesa

Los estudios sobre la Protohistoria peninsular en general y sobre la Cultura Ibérica en particular han experimentado un enorme avance en los últimos años, derivados de una verdadera revolución en la forma de entender los objetivos, métodos y prioridades de la investigación arqueológica. Nopretendemos ahora realizar una "Historiade la Investigación" de la Cultura Ibérica, sobre la que ya existen diversas síntesis publicadas, tanto en general (ENGUIX, 1973; ABAD CASAL, 1987:172-174) como sobre aspectos particulares (CHAPA BRUNET, 1980:20-70 sobre la escultura; PAGE DEL POZO 1984:41-43 sobre las imitaciones cerámicas; PEREIRA, 1988:14-71 y TARRADELL, SANMARTI, 1980 sobre la cerámica, etc.). Sin embargo, haremos un breve repaso bibliográfico de algunos trabajos que 
han marcado los pasos de la nueva orientación a la que aludíamos y que de alguna forma tienen una directa influencia en la concepción global de nuestro proyecto.

Quizá el primer hito importante tras las fases definidas por ENGUIX (a cuyo artículo remitimos para la situación anterior a 1970) es el libro de E. Llobregat (LLOBREGAT, 1972) sobre la Contestania Ibérica, donde se analizan todos los aspectos de la Cultura Ibérica en una zona definida, incidiendo con cierta amplitud en la relación de los asentamientos con su medio físico y en el concepto de Poblamicnto marcado por un enfoque socio-económico, pero sin descuidar otros aspectos más "clásicos". La influencia de este trabajo sobre ensayos posteriores ha sido grande (ABAD CASAL, 1987:174), y se manifiesta en trabajos como la Regio Edetania en la época ibérica de J. Uroz (1981). En las mismas fechas se publica en Zaragoza el libro ya citado de F. BURILLO (1980) cuyo análisis del medio geográfico sigue siendo un modelo. Por lo que se refiere a la actividad del equipo de Jaén, ya nos hemos detenido suficientemente en su aportación a la arqueología del mundo ibérico desde las primeras publicaciones de 1978 y 1981. Es de señalar como hasta 1985 todo el Alto Guadalquivir está siendo sistemáticamente estudiado, pues al proyecto de Jaén se suma el trabajo de T. Chapa y J. Pereira (CHAPA, FERNANDEZ, PEREIRA, RUIZ, 1984; CHAPA, RUIZ, PEREIRA, 1985, etc.), mientras que Córdoba presenta un verdadero vacío de investigación. La diferencia global en el enfoque de la investigación sobre la cultura ibérica es evidente si comparamos el clásico manual de A. ARRIBAS (1965) con el reciente de HARRISON (1988), desde la perspectiva de la investigación actual (CHAPA BRUNET, 1989).

Es probable que los puntos de referencia más convenientes para tener una visión sintética de la evolución de la investigación sobre la cultura ibérica, de sus intereses y de los resultados, sean cuatro reuniones: el Simposi internacional Els Origens del Món ibéric de Barcelona en 1977 (publicado en Ampurias 38-40,1976-1978); la Mesa Redonda La Baja Época de la Cultura Ibérica en Madrid, 1979 (publicada por la Asociación Española de Amigos de la Arqueología en 1981); las / Jornadas sobre el mundo ibérico de Jaén, 1985 (publicadas en 1987); y finalmente Los asentamientos ibéricos ante la romanización, 1986 (publicado 1987). La comparación de, por ejemplo, el estudio de Cuadrado sobre necrópolis (CUADRADO, 1981) y el de PEREIRA (1987)evidencia mejor que cualquier descripción el cambio de métodos, intereses y objetivos. Cualquier trabajo sobre mundo ibérico debe tener en cuenta las comunicaciones presentadas a estas reuniones.

Si miramos -aunque sólo sea por un momento- el panorama de la investigación sobre el mundo iberorromano en Andalucía, de nuevo tendremos que tomar como referente más cercano los trabajos del equipo de Jaén, aunque no hayan faltado ensayos de síntesis más general (BLAZQUEZ y GARCÍA GELABERT, 1987, BLAZQUEZ, 1981; BENDALA GALÁN, 1981), y aunque lógicamente existía una gran tradición de trabajos anteriores y realizados con otros criterios. Una definición de los propósitos de trabajo es la que proporcionó CASTRO LÓPEZ (1986), pero los resultados de un proceso centrado sobre todo en la prospección ya van viendo la luz (ROCA et alii, 1985, 1987; etc.). Además, no puede olvidarse la labor que Arteaga y otros investigadores vienen realizando en la zona.de Porcuna (ARTEAGA y BLECH. 1987; ARTEAGA, 1985).

Frente a la privilegiada posición que está adquiriendo la provincia de Jaén en el marco de la investigación de nuestra más reciente Protohistoria, la provincia de Córdoba presenta un panorama ciertamente desolador y del que sólo cabe una modificación sustancial a medio 
plazo, a partir de los proyectos de investigación desarrollados por un equipo de la Universidad de Córdoba en tomo a Almedinilla y por otro hispano-británico con centro en Torreparedones (por ejemplo, CUNLIFFE y FERNANDEZ-CASTRO, 1988). Con todo, la situación no se debe tanto a la falta de trabajos arqueológicos de campo como a la carencia, en algunos casos, de criterios científicos a medio plazo en su planificación y ejecución, o bien a una falta de publicación de los resultados obtenidos en excavaciones realizadas hace más de un decenio. Así pues, contamos con un volumen de información apreciable pero heterogéneo (por ejemplo, para la dispersión de asentamientos ibéricos, ver FORTEA y BERNIER, 1970; BERNIER et alii, 1981; SERRANOy MORENA, 1984; MUÑOZ, 1987; MORENA et alii, 1987; MORENA, 1989).

Hasta hace escasamente unos años, la contribución de la arqueología cordobesa al conocimiento de la Cultura Ibérica se ha limitado a algunas excavaciones practicadas de manera más o menos ortodoxa a lo largo del siglo pasado o principios de éste, y a datos de una extraordinaria relevancia, por lo novedoso, aportados por las excavaciones de Ategua y Colina de los Quemados, o por la recopilación arqueológica de los llamados de manera genérica "recintos fortificados". En las zonas serranas al Norte del Guadalquivir apenas si hay investigación arqueológica protohistórica digna de tal nombre, salvo algún estudio aislado sobre el Bronce Final y Orientalizante (MURILLO, 1988 e.p.) que muestra sin embargo lo prometedor de un análisis más general. La conclusión fundamental del autor es que se trata de un horizonte cultural emparentado con el mundo del Bajo Guadalquivir, al que proveería de minerales prospectados en la zona montañosa.

Lógicamente, los estudios centrados en la zona de vega del Guadalquivir son mucho más numerosos, intensos y antiguos. Basten como muestra las excavaciones de LUZON y RUIZ MATA en la Colina de los Quemados, una de las estratigrafías básicas en Andalucía Occidental (LUZON y RUIZ MATA, 1973), y el proyecto de J. Clemente Martín de la Cruz en Montoro (MARTIN DE LA CRUZ, 1985; 1987). En el otro extremo de la Provincia, en la zona de Palma del Río, se está produciendo una gran intensificación de los estudios de campo y en especial sobre el Bronce Final, a cargo de J.F. Murillo y gracias sobre todo al entusiasmo desplegado por la Administración local de dicha localidad, que incluso ha creado y consolidado una revista de alcance local y regional, Ariadna, en la que se publican trabajos de peso mucho mayor de lo que en principio cabría esperar.

Por lo que se refiere a la zona de Campiña, la investigación ha sido desigual. Ya hemos aludido a las intensas prospecciones que han dado como resultado el descubrimiento de una gran serie de yacimientos, desde grandes oppida hasta pequeños recintos fortificados, aunque dada la ausencia de un proyecto sistemático y coordinado de investigación pueda caber duda acerca del carácter completo y representativo de las mismas, sobre todo en lo que se refiere a una investigación homogénea de toda ia superficie prospectada. Salvo algún avance (BLANCO, LUZON, RUIZ MATA, 1969:151 ss.), no se han publicado los resultados de las excavaciones realizadas en yacimientos del calibre de Ategua, fundamental para una estratigrafía del Bronce Final en adelante. En cuando a los trabajos de un equipo hispano-británico en el gran oppidum de Torreparedones (CUNLIFFE y FERNANDEZ CASTRO, 1988), la secuencia estratigráfica documentada junto a la muralla en la campaña de 1987 arroja una cronología que va desde c. 1300 a.C. hasta época romana republicana, mientras que en la campaña de 1988 se excavó una estructura de carácter quizá templario en la que se halló un importante depósito de toscos exvotos, que confirman la existencia de un santuario, ya propuesta por MORENA (1989) a partir de materiales de prospección. 
Solamente el conocimiento "en superficie" de la densa red de oppida y recintos en la Campiña ha permitido realizar unos primeros mapas aproximativos de lo que pudo ser el patrón de asentamiento ibérico y el modelo de control del territorio en la campiña cordobesa. A modo de ejemplo de alguna de las grandes líneas de investigación que en la actualidad abordamos -y que en este caso acusa de manera evidente la influencia del trabajo realizado en Jaén-, recogemos un significativo párrafo de un trabajo previo de nuestro equipo (MURILLO, QUESADA, VAQUERIZO, CARRILLO, MORENA, 1989:167):

De este modo, obtenemos dos tendencias diferenciadoras de los ámbitos de la Baja Campiña y de la Alta Campiña-Subbé ticas. Por un lado, oppida de gran extensión con unos TPR que no entran en conflicio y que por lo tanto, y siempre a modo de hipótesis, podrían constituir unidades políticas y económicas autónomas, y por el otro oppida de un tamaña menor a aquéllos y cuyos TPR entran en conflicto. Esto pudo originar un proceso conducente a la creación de formas de integración basadas en la coexistencia de distintos oppida en una misma unidad política. Esto nos lleva a valorar un último factor en nuestro análisis, el del control efectivo del territorio y su defensa a través de un aparato coercitivo que asegure tanto la propia cohesión del territorio político como la disuasión frente aotros territorios políticos."

Especia] interés tienen para otra de nuestras líneas de trabajo las excavaciones practicadas por A.M. MUÑOZ (1987, con la bibliografía anterior pertinente) en el importante oppidum del Cerro de) Minguillar.en Baena (Córdoba), que constituye según su excavadora "un caso claro de transformación de un oppidum indígena en un municipium romano" (MUÑOZ AMILIBIA, 1987:63). Alude la autora a que "la falta de documentación sobre estructuras de casas tanto romanas como ibéricas en la Bética, no permite hacer demasiadas deducciones...". Quizá nuestra propia excavación de más de 600 metros cuadrados de un poblado ibérico destruido en el s. II a.C. sea de utilidad en este sentido.

En lo que toca a la cuenta de) Genil, López Palomo se lamentaba en 1980 (LÓPEZ PALOMO, 1980:34-35) del abandono de la investigación en esa zona, y comentaba: "... es presumible que tras la creación de la Universidad cordobesa comiencen a surgir nuevos equipos de arqueólogos o individualidades aisladas que subsanen el estado actual de la cuestión". Además de los trabajos del propio López Palomo en la cuenca media, ya hemos visto que desde hace tres o cuatro añoos la zona del bajo Genil en tomo a Palma del Río está siendo sistemáticamente estudiada. Por lo que se refiere al alto Genil, ya en Granada, un grupo de investigadores granadinos trabaja en dicha zona, habiéndose publicado los primeros intentos de síntesis (PACHÓN, CARRASCO, PASTOR, 1979). Los esfuerzos se han centrado sobre todo en la realización de series estratigráficas de enorme interés centradas en la transición Bronce Final-Edad del Hierro y en el impacto colonial (ver por ejemplo el caso del Cerro de la Mora en Moraleda de Zafayona, CARRASCO y otros, 1985, además del del Cerro de los Infantes en Pinos Puente).

Se equivocaba López Palomo cuando, para resaltar el abandono comparativo de la investigación en la Cuenca del Genil, aludía a la mayor intensidad de la investigación en la Subbética. centro de nuestro actual proyecto (LÓPEZ PALOMO, 1980:35; 1983:795-796). En realidad, la daba por más profunda de lo que en realidad es: ya hemos visto cómo las primeras excavaciones de Almedinilla no dieron como resultado una verdadera ampliación de nuestros conocimientos del mundo ibérico, y por lo que se refiere ai estudio de los recintos fortificados, olvida que éstos se concentran a partir de !a vertiente Norte del macizo de Cabra y ai Norte de Fuente Tójar, quedando la zona de la depresión Priego-Alcaudete 
prácticamente desprovista "de puntos sobre el mapa".

Llegamos así a la esquina suroriental de la provincia de Córdoba, a la zona de la Subbética y de la depresión Priego-Alcaudete en ella inserta. Ya hemos hablado de los primeros trabajos de excavación practicados en Almedinilla por Maraver en 1867 y por Paris y Engel en 1903, que nos dieron a conocer una gran serie de ricos materiales y la existencia de un poblado con abundantes restos, pero poco más. Así, se ha asignado a Almedinilla el dudoso honor de tener la primera necrópolis ibérica excavada en Andalucía conrefrendooficiaI(PEREIRA 1988:58; VICENT, 1984-85:40). De todos modosconviene recordar que Maraver creyó en todo momento que los restos por él hallados eran romanos (MARAVER, 1867b:328), y sólo tras las excavaciones de Paris y Engel se les asignó la etiqueta de "ibéricos".

Sin embargo, no son las de Almedinilla las primeras excavaciones realizadas en la zona. Poco antes de que Maraver excavara en septiembre de 1867 la necrópolis de Los Collados, en abril del mismo año había probado suerte en otro punto más al norte, junto a Fuente Tójar (VICENT, 1984-85; MARAVER, 1867b:309 y 327) aunque nunca publicó el Informe de excavación, oscurecidos los resultados por los más espectaculares de Almedinilla. El Informe permaneció inédito hasta que en fecha reciente A.M. Vicent lo ha rescatado del olvido (VICENT, 1984-85).

En síntesis, Maraver trabajó en la ladera Sur del Cerro de las Cabezuelas, contiguo al Cerrode las Cabezas de Fuente Tójar, hallando una extensa necrópolis de la que excavó unas cuarenta sepulturas. Con toda probabilidad, esta necrópolis corresponde al gran núcleo colindante del Cerro de las Cabezas, y por las ambiguas descripciones que nos han llegado debe haber materiales ibéricos y romanos. En esas fechas visitó también Maraver el cerro, anotando la existencia de aljibes y restos de edificios, para concluir que se trata de la lliturgicola romana, adscripción que hoy se sigue aceptando tras haberse desestimado la posterior propuesta de Navascués de identificar las Cabezas con Sucaelo (VICENT, 198485:42^3; VAQUERIZO, 1986b:352 con bibliografía pertinente).

No volvió a excavarse en la zona hasta 1934 en que a instancias de Niceto Alcalá Zamora, presidente de la República y natural de la cercana Priego, J. Martínez Santaolalla y J.M.de Navascués realizaron nuevas excavaciones (VICENT, 1984-85:41), posiblemente en la zona de muralla y en una necrópolis romana constatada en el collado que separa el cerro de Las Cabezas del de las Cabezuelas (VAQUERIZO, 1986b:352). Los resultados de estas excavaciones no se publicaron por el estallido de la Guerra Civil.

Entramos así en un hiato que no se rompe hasta 1970, año en que se publica la tantas veces citada monografía sobre los recintos ibéricos en la Bélica (FORTEA y BERNIER, 1970), que en años posteriores se ampliará con sucesivas aportaciones resultado de prospecciones cada vez más intensas (BERNIER y otros, 1981; SERRANO y MORENA, 1984; MORENA y otros, 1987; SERRANO y PICO, 1988; MORENA, 1989; MURILLOy otros, 1989). Todos estos trabajos van proporcionando información sobre literalmente centenares de asentamientos, que salvo muy escasas excepciones sólo son conocidos por prospección, y por tanto sólo nos dan una aproximación a cuestiones como extensión y cronología, por lo que las cartas de dispersión por periodos que se van elaborando deben tomarse con precaución (MURILLO y otros, 1989; MORENA, 1989). Peroen realidad toda esta información se refiere a la Campiña, y solo tangencialmente toca la subbética. Esto ya lo observaron Fortea y Bemier en 1970, cuando afirman (1970:131-133): 
"Lo que sí podemos asegurar es que al S. de Zuheros no deben existir [recintos] pues suficiente defensa es la cuerda del Monte Horquera y del Ceno de El Laderon [...] vemos que los recintos se alinean tanto en la parte N. como en la S. del río Guadajoz [,... los recintos más antiguos se sitúan en sus dos márgenes [del Guadajoz] evidenciando, por lo menos a principios del s. IV, un interés por controlarlas [...] laexperiencia nos había dicho que en el espolón del macizo subbético correspondiente a la provincia de Córdoba no existían recintos, y que estos parecen situarse en el paso natural de pequeños valles y suaves colinas que se extiende, paralelo a la cadena subbética y con su mismo buzamiento SO-NE hacia Cazorla..."

Posteriores trabajos de campo han dado como resultado la aparición de muy escasos recintos al Sur del macizo de Cabra, pero el patrón inicial se mantiene. (Ver mapa en MURILLOy otros, 1989:154y comparar con el inicial de FORTEAy BERNIER, 1970:Fig. 2). Por tanto, uno de los primeros problemas a considerar en nuestro proyecto es el de si la inexistencia de recintos al Sur de una línea Cabra-Fuente Tójar se debe a una falta de prospección -o a lo difícil del terreno en esa zona que dificultara las que se hicieran- o a una escasez real de yacimientos.

No es hasta la década de los ochenta cuando la investigación en La zona de PriegoAlcaudete, al Sur del macizo de Cabra, se reactiva en varias direcciones. Por un lado, A.M. VICENT y A. MARCOS POUS realizaron en 1977 y 1980 nuevas excavaciones en la zona del Cerro de las Cabezas de Fuente Tójar, concretamente en el paraje denominado Los Villalones o Los Torviscales, zona baja inmediatamente al Noreste del cerro, donde se excavó una necrópolis ibérica datable al menos desde el s. VI a.C. (por un alabastron de pasta vitrea) y como mínimo hasta el s. IV a.C. (cerámica ática). La memoria no se ha publicado todavía, y sólo contamos con un avance publicado en 1983 (MARCOS POUS y VICENT, 1983), así como algunos trabajos centrados en los materiales conocidos por excavaciones clandestinas (VAQUERIZO, 1986a, 1986b).

También referidos al mundo ibérico son diversos trabajos de D. Vaquerizo dedicados por un lado a materiales diversos conservados en el Museo de Priego, que confirman la existencia de yacimientos en puntos tan estratégicos como el Cerro del Castillo en Carcabuey o el Cerro del Puerto en las Lagunillas (VAQUERIZO, 1983-84; 1987); y por otro a la Cueva de la Murcielaguina, importante asentamiento prehistórico (GAVILÁN, 1987: 32 ss.) donde la aparición de fragmentos de exvotos ibéricos y de cerámica utilizable en libaciones ha llevado a plantear la probable existencia de una cueva-santuario ibérica similar a las existentes en el Levante peninsular (VAQUERIZO, 1985b).

Pero no ha sido sólo el periodo ibérico el que ha visto renovados sus estudios durante los años ochenta. En el mismo periodo las etapas prehistóricas han sido también intensamente investigadas, como prueban, a título de ejemplo, los trabajos de M.D. Asquerino dedicados a la Cueva de los Mármoles (Priego), o los estudios de B. Gavilán (ASQUERINO, 1985a, 1985b, 1986; GAVILÁN, 1984,1987, etc.).

En cambio, la etapa romana ha seguido mostrando un notable vacío, que sólo está siendo rellenado a partir de nuestros propios trabajos en la zona de Almedinilla. Únicamente cabría destacar, aparte de obras generales referidas al conjunto de la provincia (RODRÍGUEZ NEILA, 1985), la reciente monografía de L. Segura Arista referida a la antigua Igabrum, la Cabra actual (SEGURA, 1988), que toca aspectos sumamente interesantes desde el punto de vista arqueológico, como la distribución del famoso **mármol rojo" de Cabra. 


\section{El ámbito geográfico}

En la provincia de Córdoba, y de Norte a Sur, pueden distinguirse cuatro grandes unidades (Figura 1): la Sierra, al Norte del Guadalquivir -zona que tiende a bascular hacia Extremadura y La Mancha incluso hoy en día-; la vega del Guadalquivir, prolongada a Este y Oeste hacia Jaén y Sevilla; la Campiña, al Sur del río; y por último las Sierras Subbéticas, que separan el Sureste de Córdoba del alto Genil y a la vez introducen las montañas granadinas y malagueñas. El límite entre la alta Campiña y la Subbética es impreciso, pero un límite aproximado sería una línea sinuosa que uniera Baena con Puente Genil pasando por Doña Mencía.

La Subbética cordobesa se caracteriza por un relieve (Figura 2) sumamente accidentado, con sierras no muy altas en lo absoluto (en tomo a los 1.000 metros) pero sí escarpadas (cumbres de perfiles aristados, tajos verticales y profundos cañones); el clima es irregular, con una pluviosidad comparativamente elevada; los suelos presentan una distribución laberíntica, y en los macizos de afloramientos calizos abundan las formaciones kársticas, que a su vez propician la aparición de numerosos manantiales y fuentes (creadas por una combinación de abundantes lluvias y alto coeficiente de infiltración, ORTEGA ALBA, 1975:27 ss,). Del mismo modo, abundan las cuevas, embudos, simas y dolinas (GAVILÁN, 1984:22).

La Subbética se compone, en rasgos generales, de los siguientes elementos (Figura 2):

a) Un gran espolón montañoso de dirección Sureste-Noroeste, que separa los cursos aproximadamente paralelos del Guadajoz al Norte y del Genil al Sur. El macizo de Cabra, extremodel espolón, limita por el Norte el área de nuestro estudio. En su ladera septentrional es donde se encuentra una línea de recintos fortificados que ya no penetran más hacia el Sur.

b) Sierras meridionales (Gaena, Rute, Horconera, Alba yate) que en su ladera Sur vierten sus aguas al Genil y en la norte dan lugar al nacimiento de una serie de cursos de agua, como el Almedinilla, Salado y Zagrilla).

c) Depresión Priego-Alcaudete, zona baja entre estos macizos elevados, cerrada al norte por el macizo de Cabra y Sierra Alcaide, y al Sur por las sierras antedichas. Sus salidas naturales son hacia el Norte por la zona de Fuente Tójar y hacia el Oeste por el río Cabra. Esta zona a su vez adquiere una composición digitada en tres valles convergentes hacia el Norte (los del Zagrilla, Salado y Almedinilla), que vienen a unirse en la zona de Alcaudete, donde la confluencia de Salado y San Juan da origen al Guadajoz. Entre el Almedinilla y Salado se encuentra la pelada Sierra de los Judíos, y entre el Salado y Zagrilla la Sierra Leones. Las comunicaciones laterales quedan facilitadas por un pasillo que va de Carcabuey a Priego y Almedinilla, además de por otro menor al norte, junto a Fuente Tójar.

Esta zona un tanto cerrada geográficamente, pero a la vez con buenas comunicaciones hacia la Campiña cordobesa y jiennense, el Genil y Málaga e incluso hacia Granada por el nacimiento del Almedinilla, es la que resulta objeto de nuestro estudio.

El clima cordobés es subcontinental semihúmedo, con inviernos templados-fríos y veranos secos y calurosos. Hay sin embargo grandes variaciones comarcales debidas a la topografía: la zona de Priego-Rute es la más continental de la provincia, con una mínima media en enero de 2 grados, y una máxima media en julio de 33 (VAQUERIZO, 1988a:53). La pluviosidad en la Subbética es alta con respecto a la media de Andalucía, facilitada por el relieve. Debido a esto y a la alta infiltración, la red hidrográfica no es muy tupida pero sí de caudal abundante, lo que determina áreas reducidas de fértil vega, donde hoy abundan 
cultivos hortícolas y frutales. El régimen fluvial sufre severos estiajes en enero y agosto, pero las fuertes reservas hídricas de las Sierras han supuesto hasta hace pocos años una mayor regularidad de caudal que en otros ríos de peor alimentación. El Almedinilla, por ejemplo, corre todo el año, y hasta hace muy poco era mucho más caudaloso, y capaz de abastecer a una población. Aunque la zona Sur de Córdoba es así uno de los islotes de relativa importancia pluviométrica de Andalucía (GAVILÁN, 1984:25), las lluvias de invierno e incluso de primavera, torrenciales, pueden ser muy destructivas, con desbordamientos incluidos.

Los suelos de la zona son de calidad variable para el cultivo, desde los litosuelos calizos de la sierra de los Judíos, inadecuados para el cultivo, hasta las fértiles vegas del Almedinilla o Salado, pasando por las tierras pardas calizas y rendsinas de la zona de Almedinilla. En general, sin embargo, la aptitud para el cultivo puede considerarse mediana, sin llegar por supuesto a las posibilidades agrícolas de la Campiña. Junto a los cereales, las zonas de vega permiten un amplio abanico de cultivos hortofrutícolas.

No disponemos todavía de datos paleobotánicos que permitan determinar la vegetación antigua, pero en cualquier caso, la reconstrucción de la vegetación potencial climax en la Subbética es más sencilla que en la Campiña, ya que por su complicada topografía se conservan algunas zonas con vegetación natural. Son frecuentes, incluso en la toponimia, los acebuchales, carrascales, quejigales, etc. El predominio debió ser de especies de hoja perenne del género Quercos, en especial encinas, quejigos y alcornoques. Hoy en día, la deforestación y la roturación están destruyendo esta vegetación, sustituyéndolapor extensos olivares que favorecen el lavado erosivo del escaso suelo. Por el contrario, la precaria tecnología agrícola prerromana habría mantenido los litosuelos y rendsinas en condiciones bastante favorables -por la limitada erosión antrópica derivada de la utilización de arado de tracción animal- para la obtención de adecuadas cosechas cerealísticas y también para mantener una vegetación espontánea capaz de mantener una cierta cabana ganadera, fundamentalmente de ovicaprinos (ORTEGA ALBA, 1975).

Hoy en día predomina, en lo referente a la ganadería, una limitada cabana ovina y, sobre todo, caprina, distribución que no debe diferir mucho de la antigua. La caza disponible es escasa, y se centra en conejo-liebre y aves. En este caso sí disponemos de un análisis preliminar de un conjunto de huesos de animales recuperados en la excavación de 1985 en el Cerro de la Cruz. Estos huesos pertenecen probablemente a un basurero situado al exterior de una vivienda, en la zona denominada por nosotros D-16 (contextos A,D,E). Los análisis fueron realizados por el Dr. A, Montero Agüera, Prof. Titular de Anatomía y Anatomía Patológica comparada de la Universidad de Córdoba, y pese a tener un carácter limitado y preliminar pueden servirnos para dar una idea previa de la cabana y de los productos de caza en época ibérica (VAQUERIZO, 1988a, 534-541): se han recuperado 18 fragmentos de ovicaprino (cabra), 17 de conejo-liebre, 1 de suido y nada menos que 127 de cérvido, además de 26 huesos de cánido.

La riqueza en minerales es muy escasa en absoluto y también si se compara con las zonas de Sierra Morena (Cástulo, Alcaracejos...) (FORTEA y BERNIER, 1970:132). A pesar de ello, hay algunos minerales propios (VAQUERIZO, 1988a:nota 5), sobre todo ocre y algo de hierro en la zona del nacimiento del Guadajoz, en yacimientos catalogados por la cartografía moderna como improductivos, lo que no necesariamente se aplica a la Antigüedad. Hay también un filón bastante potente de piritas auríferas en la Sierra de Vizcantar, muy próxima a Almedinilla, que no se pusieron en explotación en este siglo por la falta de 
rentabilidad (la riqueza de las vetas no justificaba, al parecer, traer un ferrocarril).

Por lo que se refiere a la demografía, hasta hace poco, y desde la colonización de la zona en el s. XVIII a partir de Priego, ésta ha sido bastante marginal (ORTEGA ALBA, 1975:167), con predominio dé la dispersión en numerosos cortijos distribuidos anárquicamente, aprovechando enclaves favorables desde el punto de vista de la agricultura, agua, etc... Hoy en día, sin embargo, la concentración es mayor, y el paisaje está lleno de cortijos abandonados. Por to que se refiere a periodos anteriores, en la Edad Media entre el s. XIII y finales del XV esta fue una zona fronteriza entre Granada y Castilla, con población escasa y dedicada fundamentalmente a la ganadería, actividad que favorecía la movilidad y protección frente a las razzias de saqueo y destrucción. Si nos remontamos más aún en el tiempo, los resultados preliminares de las prospecciones que venimos realizando parecen indicar un poblamiento del Bronce Final escaso y bastante concetrado, un poblamiento ibérico pleno con características similares, para dar paso a un poblamiento ibérico de Baja Época más denso y disperso, en un proceso que culminará con una gran densidad y dispersión de yacimientos romanos a lo largo de los cursos fluviales.

Aspecto importan te y con el que concluimos este apartado dedicado al medio geográfico, es el de las vías de comunicación (Figura 4). Es en principio casi un ritual arqueológico insistir en que el yacimiento que uno mismo excava, o la zona que uno prospecta, se ubica sobre una importante vía de comunicación o en una zona nuclear por su importancia mineral o agrícola. Sin embargo, la zona que abarca nuestro proyecto de investigación difícilmente puede considerarse una zona nuclear, pues se aparta mucho de los grandes ejes del Guadalquivir y del Segura, e incluso de algunos secundarios, como el Guadiana Menor y el Genil (Figura 1). Del mismo modo, no es una zona especialmente fértil, y se aleja mucho de la capacidad productora de mineral de zonas como Sierra Morena, Huelva o Cartagena, En este sentido, quizá sólo pueda tener un papel en las comunicaciones entre la costa granadina-malagueña y el Alto Guadalquivir. Por supuesto que hay vías de comunicación, pero de carácter secundario, más bien comarcal y local. Y sin embargo, los yacimientos protohistóricos y romanos han proporcionado desde antiguo abundantes materiales de gran calidad, y encontramos yacimientos de gran envergadura, como el propio Cerro de las Cabezas de Fuente Tójar.

Para las descripciones de rutas que a continuación se darán se ha utilizado, además de la amplia bibliografía que venimos citando, el viario romano, los geógrafos árabes, la topografía y toponimia, etc. (VAQUERIZO, 1988a:65 ss.).

La gran vía natural de comunicación en Andalucíaes el valle del Guadalquivir, que corre en sentido Este-Oeste. En función de ella se articulan otras rutas naturales que sabemos de cieno fueron utilizadas en la Antiguiedad. En primer lugar tenemos la ruta del Genil, también de sentido Este-Oeste y convergente al Guadalquivir. Desde la rica zona minera de Linares (Cástulo) partían tres grandes rutas hacia la costa; una por el Guadiana Menor y Baza hasta la costa de Granada-Almería; y otra, más incómoda topográficamente (FORTEA y BERNIER, 1970:133), hacia Cartagena por el Segura. Una tercera vía unía la zona de Cástulo con Málaga a través de Obulco (Porcuna), iponuba (Baena), Igabrum (Cabra) y Anticaria (Antequera).

Baena resulta para FORTEA y BERNIER (1970:132) un centro importante de comunicaciones, en tanto que es atravesada por la gran ruta Cástulo-Málaga, y además cuenta con otra vía por el Guadajoz en dirección a Corduba. Pensaban precisamente estos autores que los recintos fortificados pudieron construirse en función del control de la vía 
NE-SO de Castillo a Málaga y de la vía NO-SE Córdoba-Baena por el Guadajoz.

No se debe olvidar tampoco, por último, la vía romana -presumiblemente de raíces más antiguas- que iba de Córdoba a Málaga vía Ulia (Montemayor)-Ipagrum (Aguilar)Monturque-Benamejí para unirse allí a la vía Obulco-Malaca por Anticaria.

Por otro lado, otra vía natural parte de la zona de Obulco hacia Manos, y desde allí hacia Granada por la ruta Alcaudete Alcalá la Real-Genil a la altura de Granada (RUIZ y MOLENOS, 1984b:189-190).

En todo este entramado la Subbética queda en posición algo marginal, pese a lo cual su comunicación con la gran ruta Obulco-Malaca es fácil por dos puntos: al Norte por la zona de Fuente Tójar-nacimiento del Guadajoz-Baena y al Oeste por la vía transversal AlmedinillaPriego Carcabuey-Cabra. Por otro lado, no pueden despreciarse otras cuatro posibles vías secundarias de comunicación hacia el Sur: una pudo ir desde la zona de Fuente TójarZagrilla-Carcabuey y desde allí por entre las Sierras de Gaena y Rute hacia Benamejí y el Genil. En segundo lugar existe otra ruta paralela a la anterior, por la zona de Las Lagunillas, entre las sierras de Horconera-Rute y la de Albayate, que da inmediatamente al Genil; otras vías menores pueden ir por el valle del Almedinilla hacia el Sur y desde la zona del Cerro de la Cruz hacia el Este, hasta Alcalá la Real para luego descender hacia Granada. De todas estas rutas la que tiene más visos de haber sido intensamente utilizada, al menos desde el s. VII a.C. es la de Málaga-Antequera-Benamejí-Carcabuey-Fucnte Tójar-Baena y Guadajoz, para desde allí poder elegir entre Córdoba o Porcuna. Entre los elementos arqueológicos que nos enmarcan esta ruta están la urna de tipo Cruz del Negro de Carcabuey (VAQUERIZO, 1983-84) o la espada publicada por Harrison también procedente de Carcabuey (HARRISON, 1974-75). Más defínitoria aún parece la presencia de puntas de flecha de doble ñto y arpón de procedencia oriental, fechadas sobre todo en el s. VII, que aparecen a millares en Benamejí, y también se dan en Carcabuey, Fuente Tójar y Baena (QUESADA, 1989; MURILLO y RUIZ LARA, e.p.).

Es importante recordar, por último, que la distribución conocida de muchos de los oppida de la campiña jalona las rutas que venimos describiendo.

\section{Objetivos del proyecto}

Sintetizando al máximo, los objetivos generales (no descendemos ahora a las cuestiones concretas de cada problema) de nuestro proyecto se pueden sintetizar así:

A) Estudio de la distribución del poblamiento y ordenación del territorio en un proceso diacrónico, desde el Bronce Final hasta la plena Romanización, poniendo énfasis en los siguientes aspectos: modos de explotación económica del territorio; control político territorial y cambios de dichos aspectos en el tiempo.

B) Análisis detallado -del que la arqueología andaluza está especialmente necesitadode! urbanismo ibérico a través de la excavación en extensión del poblado del Cerro de la Cruz en Almedinilla. En dicho análisis incluimos también el nivel microespacial, con especial interés en la determinación funcional de los espacios.

C) Obtención de algunas estratigrafías en yacimientos seleccionados para consolidar nuestro conocimiento global del proceso diacrónico de ocupación y control de territorio en el área objeto de estudio.

D) Crear una buena Tipología -que vaya más allá de la mera Clasificación- de materiales ibéricos, susceptible de ser comparada con las clasificaciones y/o Tipologías conocidas en 
las tres principales zonas de contacto (Campiña. Valle Medio del Genil, Curso alto del Genil- Granada).

E) Conservación, restauración y exhibición al público de los yacimientos excavados en extensión, así como de ios materiales hallados. Énfasis en la conservación y divulgación del Patrimonio, fomentando aquellos aspectos que puedan ser de interés turístico, en su doble vertiente de interés cultural y de avance económico de una zona tradicional mente marginal.

\section{Fases previstas de trabajo}

Las Fases de trabajo no están siguiendo un desarrollo lineal (una actuación después de haber concluido la previa) y regular (ritmode trabajo constante y uniforme), sino en paralelo e irregular (a veces se desarrollan dos o más actividades a la vez y en ocasiones ha habido que interrumpir un trabajo para volcar los esfuerzos en una excavación de urgencia) debido a una serie de factores:

a) La forma en que nuestro Proyecto se ha ido desarrollando (ver el apartado referido a la Génesis del mismo).

b) Características de nuestros objetivos (ver apartado de objetivos) que no exigen la sucesión de fases.

c) Acontecimientos imprevistos (saqueos a gran escala de excavadores clandestinos; modo y cuantía de la financiación disponible en cada momento; obras públicas que hacen surgir a la luz una importantísima villa y necrópolis romanas...).

Sin embargo, las fases -o quizá mejor dicho apañados- de actuación pueden esquematizarse así:

A) Excavación sistemática en extensión del Cerro de la Cruz (ver Objetivos B, D y E).

B) Excavación de Urgencia (hasta ahora se han desarrollado 10 meses de trabajo, considerablemente más que en una excavación sistemática normal) en la Villa del Ruedo. El futuro de los importantísimos restos, afectados por la construcción de una carretera, dependerá de las decisiones que tome la Administración. La excavación en extensión de un yacimiento de estas características no estaba prevista inicialmente, pero el desarrollo de los acontecimientos y la importancia de los restos lo hizo inevitable.

C) Vallado, protección y consolidación provisionales de los yacimientos citados (ver Objetivo E).

D) Restauración y exhibición al público de ios yacimientos citados (ver Objetivo E). En el caso del Cerro de la Cruz está previsto aprovechar dos circunstancias favorables, como son la construcción prevista de una carretera asfaltada hasta la cima del cerro de la Cruz para el servicio de un Transformador de Televisión, y que permitiría acceder en coche hasta el mismo yacimiento -hecho raro en un poblado de cerro-; y la constitución el 22 de octubre de 1987 del patronato de Turismo de la Subbética Cordobesa, a raíz de la declaración de la comarca como Parque Natural de Andalucía.

E) Prospección sistemática de toda la zona abarcada por el Proyecto e intensiva de un muestreo seleccionado (Objetivo A).

F) Prospección con sondeo en el Cerro de las Cabezas, al que todo apunta como centro más importante de la zona, y en el que hay documentado por prospecciones de superficie un poblamiento que abarca desde el Bronce Final hasta más allá del final del mundo romano, y quizá incluso desde el CaJcolílico.

A más largo plazo está planteadas las siguientes posibilidades: 
G) Eventualmente pudiera hacerse necesaria una excavación sistemática del Cerro de las Cabezas, sobre todo para el estudio del sistema de fortificaciones y de la etapa plenamente romana, que complementara el sondeo estratigráfico realizado.

H) Prospección con sondeo en uno o varios de los siguientes yacimientos: Cerro del Castillo de Carcabuey; Cerro del Puerto en Lagunillas; Camino del Tarajal en Priego. Buscamos con ello documentar las fases del Bronce Final y Orientalizante, así como el tránsito a la plena época de la Cultura Ibérica, etapas que hasta el momento permanecen prácticamente inéditas.

Es evidente que, de manera simultánea a todas estas actuaciones, preveemos ta publicación de resultados parciales y finales a medida que estén disponibles. De la misma forma se ha previsto la constitución de un banco de datos informatizado con toda la información obtenida que previsiblemente -por su volumen- no pueda ser publicada por los medios tradicionales. Un banco de datos de estas características podría poner al servicio de otros investigadores información de base y de detalle no accesible a través de otros medios.

Por otro lado, todas las actuaciones llevan aparejadas actividades integradas de análisis de todo tipo: antropológicos, arqueozoológicos, palínológicos, análisis de pastas cerámicas, etc., algunas de las cuales ya están en curso. De la misma forma, hemos dispuesto durante 1989 de un restaurador trabajando en gabinete con los materiales exhumados, tratando de garantizar su conservación en las mejores condiciones posibles.

Actuaciones llevadas a cabo hasta el momento

\section{1) Prospección arqueológica superficial}

Del enunciado de Objetivos se deduce fácilmente que la realización de prospecciones de superficiecon criterios modernos (un brevísimo resumen en FERNANDEZ, 1989:50 ss.) es parte esencial de nuestro trabajo.

Ya en 1985-86 uno de nosotros (D. Vaquerizo), con subvención de la Dirección General de Bienes Culturales de la Junta de Andalucía, llevó a cabo una primera campaña de prospección superficial, cuando todavía el proyecto de trabajo no estaba definido en los términos actuales, y casi a título individual. Este primer trabajo, sin embargo, pretendía un acercamiento preliminar a los grandes yacimientos de la zona, conocidos desde antiguo por la bibliografía o evidentes por su entidad física. Los resultados (VAQUERIZO 1987) mostraron la importancia de algunos yacimientos clave: Cerro de las Cabezas, Camino del Tarajal y La Almanzora en la zona norte, controlando el tránsito a la campiña; Carcabuey y Las Lagunillas al Oeste y Sur, sobre las vías de paso hacia el Genil; Cueva de la Murcielaguina, en las Angosturas, único paso entre Priego y Fuente Tójar y posible cuevasantuario ibérica.

A lo largo de 1988, y en una fase de trabajo de gabinete, se recopiló la información publicada e inédita disponible sobre prospecciones efectuadas en el marco geográfico del Sureste de Córdoba, para integrar nuestro trabajo en un contexto mayor. Los primeros resultados y planteamientos de hipótesis a contrastar fueron publicados poco después (MURILLO y otros, 1989). Quizá lo más notable a primera vista era la comprobación de que el poblamiento protohistórico en la zona de Campiña parece denso (sobre todo al Norte del Guadajoz y hacia el Guadalquivir), mientras que desde la zona de Sierra de Cabra hacia el Sur existía hasta hace un par de años un gran vacio (Figura 4). Nuestro propósito con las 
prospecciones que ahora comentaremos ha sido por un lado determinar si ese vacío población al era fruto de la falta de investigación o si por el contrario se debía a una escasez de poblamiento en la zona en comparación con la Campiña; y por otro avanzar en el cumplimiento de nuestro objetivo "A".

$\mathrm{Si}$ bien estos acercamientos iniciales tuvieron la virtud de ofrecer un primer panorama general, era evidente que se requería un trabajo de campo a mucha mayor escala y de mayor detalle. Por ello se ha realizado una primera prospección sistemática durante el otoño de 1989, abarcando la cuenca del río Almedinílla y el tramo del San Juan hasta que desemboca en el Guadajoz. El equipo empleado ha sido amplio, con doce personas realizando labor de campo y otro equipo en laboratorio realizando la clasificación preliminar del material.

Las técnicas de prospección de campo por equipos que recorren a pie el terreno -por no hablar de la utilización de métodos físico-químicos, fotografía aérea, etc.- han alcanzado un elevado nivel de desarrollo en los últimos años, tanto a nivel conceptual como práctico. Conscientes de las limitaciones que afectan a la fiabilidad de los resultados (dependientes de la conservación diferencial de los lugares arqueológicos y del descubrimiento diferencial de los mismos), hemos procurado diseñar un sistema de prospección adecuado a las características morfológicas del área a prospectar, al tiempo y recursos disponibles y a las características del equipo de prospección. Los equipos de campo han contado con un número ñjo de personas, y siempre los mismos dentro de lo posible, trabajando en condiciones similares en todas las zonas prospectadas.

En este caso se ha utilizado una prospección no aleatoria de una treintena de zonas (Figura 5) que fueron consideradas susceptibles de haber ejercido una importante atracción para el poblamiento humano, a partir de un análisis de informes locales, topografía y toponimia. En estos puntos se trazaron una serie de transects que han constituido la unidad básica de prospección, combinada en algunos casos con el sistema radial con centro en una cota prefijada. Cada transect ha sido definido por una serie de vectores-tantos como prospectores con separación equidistante y dotados de un módulo (distancia a recorrer) y de un rumbo (orientación respecto al norte magnético).

Con el fin de contrastar los resultados de esta prospección se han seleccionado de modo aleatorio una serie de cuadrículas de 1.000 metros de lado, que han sido prospectadas de manera sistemática e intensiva mediante un sistema de vectores: realizar grandes transects que cubran valle, laderas y cimas es impracticable e inútil por lo escarpado del terreno en muchos puntos y la fuerte erosión.

Todos los yacimientos localizados -de los que ahora no haremos mención detallada- se han documentado mediante el uso de fichas estandarizadas que recogen no sólo el tipo de materiales hallados sino toda una serie de informaciones -ubicación, dominio visual, uso actual del suelo, etc.- según los criterios que se han hecho generales en los últimos años.

Del análisis preliminar de los resultados de la prospección de 1989 (Figura 6) se desprende un patrón de asentamiento concenvado a lo largo del río Almedinilla y de la margen izquierda del San Juan. El poblamiento prehistórico viene definido por un posible taller de sílex localizado en Cerro Alcalá, con algunos núcleos agotados y restos de talla. Más definitorio es el material ítico recogido en la Loma de Porras, con núcleos, hojas con o sin retoque, lascas y restos de talla.

En el Calcolítico se encuadran los dos importantes asentamientos de la Mesa de Fuente Tajar -que será prospectado con detenimiento en la campaña de 1990 por hallarse más bien en la cuenca del Salado- y el del Castillarejo de Almedinilla. En éste último se ha localizado 
abundante material cerámico y lítico, entre el que destacan vasos hemiesféricos, globulares y platos o fuentes de borde engrosado, con una tipología amplia. La ausencia de fuentes carenadas y otras formas arcaicas nos inclina a situar este poblado en el Calcolítico PlenoFinal, aunque debe enfatizarse el carácter meramente indicativo de estas apreciaciones preliminares.

La Edad del Bronce presenta un vacío en nuestros mapas de distribución de esta zona, aunque existen yacimientos encuadrables en este periodo en Priego, hacia el Oeste. La escasez de Bronce Final y Orientalizante es quizá significativa respecto a la existencia de un poblamiento bastante concentrado. Sólo el Cerro de las Cabezas de Fuente Tójar ha proporcionado algunas escasas cerámicas bruñidas a mano y grises a tomo, lo que se suma a hallazgos anteriores de cerámicas polícromas con decoración figurada y de puntas de flecha de arpón y doble filo, ambos buenos indicadores del Orientalizante en la Campiña de Córdoba. Este temprano poblamiento del Cerro de las Cabezas refleja una primacía respecto al espacio estudiado que perdurará al menos hasta época romana.

Ya en plena época ibérica se une al Cerro de las Cabezas el poblado del Cerro de la Cruz, articulándose el poblamiento ibérico en torno a ambos yacimientos, sin que las prospecciones superficiales hayan proporcionado nuevos puntos con ocupación ibérica clara, a excepción del Molino de Núñez, donde el material extraído por obras de cantería nos remite a una cronología de Baja Época Ibérica anterromana, similar a la documentada en el Cerro de la Cruz.

El patrón concentrado y algo escaso que venimos comentando parece romperse con la romanización, cuando proliferan los yacimientos, algunos de gran interés como el Cerro de la Atalaya, Cota 601 y Cota 519, con un variado repertorio de terra sigillata. A partir de este momente y hasta época bajoimperial se advierte también la proliferación de villae a lo largo de la vega del Almedinilla, con un tipo de poblamiento del que es paradigmático la recientemente excavada villa de El Ruedo, con una fase julio-claudia pero con perduración hasta más allá del s. IV d.C.

Sin embargo, pese al hallazgo de numerosos yacimientos, en especial romanos, los resultados han sido inferiores a loque cabría esperar dada ladensidad de la prospección: hay periodos (BF, ibérico) con notable poca representación. Hay puntos donde la lógica y el contexto geográfico nos hacían suponer la existencia de yacimientos y que en la Campiña hubieran implicado casi con seguridad la documentación de un "recinto", y que sin embargo no han dado ni un sólo fragmento, como por ejemplo en la sierra de Vizcántar, junto a Almedinilla, que domina la vega de forma inmejorable, con suficiente espacio en un espolón, una mina de piritas auríferas y agua cercana.

Creemos, en resumen, que los resultados de esta campaña de prospección arqueológica superficial han sido muy satisfactorios. El reconocimiento de una veintena larga de yacimien toses sólo un aspecto a integrar dentro del más amplio estudio de aprovechamiento del espacio, patrón de asentamiento, etc. desde el Calcolítico hasta la Romanización. No es sin embargo una prospección definitiva: la erosión, labores agrícolas, etc. pueden poner al descubierto nuevos yacimientos; y además es evidente que no se ha recorrido sistemáticamente todo el terreno, por lo que es imprescindible una labor de seguimiento continuado, volviendo sobre los mismos sitios y sobre otros nuevos, algo garantizado por la presencia continuada en la zona de miembros de nuestro equipo al haberse centralizado el trabajo de laboratorio en la localidad de Almedinilla.

Por otro lado, ya está prevista para 1990 la realización de otra campaña de prospección 
en las cuencas de los ríos Salado y Zagrilla, para completar una primera visión general y a la vez detallada del territorio. Al tiempo, nuestro trabajo se ve de algún modo completado por el realizado al otro lado del límite administrativo de Jaén por un equipo jiennense \{MONTILLA,RISQUEZyotros 1989), que ha prospectado toda la zona de Alcaudeteal Sur del río Víboras.

\section{Excavación arqueológica sistemática en el Cerro de la Cruz}

Ya hemos visto en el apañado dedicado al origen de nuestro proyecto que la primera campaña en el poblado desde 1903 fue realizada en 1985 (VAQUERIZO, 1985a, 1990). El objetivo de esta primera intervención fue dotar de un contexto nuevo (el original se había perdido) a los materiales de la vecina necrópolis de los Collados y a los procedentes del propio poblado excavados por París y Engel. En los sondeos practicados, totalizando setenta metros cuadrados se documentaron, en esencia, los siguientes hechos:

a) Destrucción generalizada de varias de las terrazas en que se dispone el poblado por parte de excavadores clandestinos que en su audacia habían llegado a utilizar una pala excavadora, destruyendo muchos centenares de metros cuadrados de yacimiento hasta profundidades de más de dos metros, por increíble que pueda parecer.

b) Existencia de un poblado ibérico de Baja Época con sus estructuras en general muy bien conservadas, con muros de adobe y tapial sobre zócalo de piedra que llegaban a superar los dos metros de alzado conservado.

c) Posible existencia de un poblado anterior, quizá remontable al s. IV a.C, muy destruido.

d) Ausencia de materiales romanos.

e) En zonas localizadas, restos de estructuras y basureros islámicos.

f) Presencia de varios aljibes de gran capacidad excavados en la roca, de planta elipsoidal.

g) Ausencia de fortificaciones visibles. Lo que hubiera podido ser resto de una muralla resultó tras su excavación un gran muro de contención moderno, colocado para sostener las tenazas en cultivo. No se pudo confirmar la información de FORTEA y BERN1ER (1970:53) cuando aluden a un "amurallamiento ciclópeo, hoy muy destruido, de grandes bloques, la mayoría fuera de su sitio".

Tras esta primera campaña se han realizado otras dos a mayor escala, en 1987 y 1989 , tras las que contamos ya con una superficie superior a los 600 metros cuadrados excavados. La técnica ha sido la excavación en área sobre una retícula teórica de 5x5 metros, y no la cuadrícula con testigos tipo Wheeler que, dadas las condiciones del yacimiento, resulta más un engorro que una ayuda. La unidad básica deexcavación no ha sido, por supuesto, el plano artificial, ni tampoco el elusivo "estrato", sino la unidad menor que llamamos "contexto", siguiendo en esencia el método Harris.

En síntesis, podemos afirmar que contamos con una excavación única en Andalucía de un poblado ibérico inmediatamente anterromano de Baja Época, abandonado tras una destrucción violenta por incendio en tomo a mediados del s. II a.C. y nunca reocupado -ni siquiera hubo rebuscas entre los escombros de las casas-, lo que nos permite documentar in situ todos los materiales de la vida doméstica e industrial a una escala casi inédita: centenares de pesas de telar en verdaderos almacenes, decenas de ánforas completas en sus vasares; molinos con el grano calcinado en sus plataformas; aljibes con su revoco y 
cubrición; muros de adobe con sus capas de enlucido de cal, etc., lo que nos proporciona una oportunidad inmejorable de realizar toda una sene de estudios al nivel genéricamente denominado "micro".

Aparte dedos grandes áreas centrales (Figura?), se ha realizado una serie de tres sondeos en puntos diferentes del poblado para determinar su extensión y características en diversas zonas. Dos de ellos han revelado niveles arqueológicos destruidos por la erosión, mientras que un tercero ha proporcionado resultados idénticos a los del área central.

Sería imposible precisar aquí los detalles de cada departamento excavado. Baste señalar que nos encontramos ante una organización atenazada de la ladera del cerro, en la que cada terraza contiene una hilera de edificaciones, cuya delantera es un ancho muro de contención que a su vez sirve de pared de fondo a la hilera de edificaciones de la terraza inmediatamente inferior. Hemos podido documentar calles en sentido de las curvas de nivel, así como una posible calle en cuesta con la función de unir las terrazas. Todo el conjunto excavado parece un área dedicada a la molienda y almacenamiento de granos, a la fabricación y depósito de pesas de telar y otros productos, más que un área doméstica, pero ello puede ser simplemente una impresión debido a la enorme riqueza de materiales que en poblados ibéricos abandonados lentamente no se produce ni por asomo. Cuando, por el contrario, se encuentra una habitación destruida violentamente, suele sorprender por la cantidad de materiales que contiene (cf. BURILLO y SUS, 1986). Entre los materiales arqueológicos cabe destacar, además de la riqueza y variedad del material cerámico (que incluye, quizás sorprendentemente, piezas de tipos característicos del Sureste, como vasos de borde dentado y toneletes), la gran cantidad de huesos acumulados en un basurero depositado sobre un posible callejón justo a! sur del gran muro que hemos denominado 25 (espacio "S"), que permitirá un estudio arqueozoológico detallado. Es de igual interés la presencia de abundante grano calcinado, también susceptible de estudio, así como de muestras de cuerdas y esteras de esparto, maderas calcinadas y otros residuos de materias orgánicas.

\section{Excavación arqueológica de urgencia en la villa romana de ' El Ruedo"}

La Intervención Arqueológica de Urgencia en la zona conocida como "El Ruedo'* (Almedinilla, Córdoba) se planteó a causa de las obras de construcción de la nueva carretera Priego de Córdoba-Granada, cuyo trazado propuesto afectaba dicho yacimiento romano, suponiendo su total destrucción. Por ello, y pese a que en principio no estaba prevista la actuación de este yacimiento, el 13 de septiembre de 1988 solicitamos la apertura de un expediente de Intervención de Urgencia, y el 3 de octubre comenzó una excavación que, con multitud deavatares administrativos, se prolongó hasta ñnales de julio de 1989 (VAQUERIZO, 1990b).

La existencia del yacimiento romano conocido popularmente como "El Ruedo" o "Bergara" es conocida desde antiguo. Se trata de una zona amesetada, aunque en pendiente, situada en la ladera Suroriental de la Sierra de los Judíos, a escasa distancia de Almedinilla. Algunas noticas sobre la aparición de restos en esta zona nos las da ya RAMÍREZ DE ARELLANO (1904:1238 ss.). De la misma manera, en 1904, una delegación francesa, dirigida por P. Paris y A. Engel desarrolló varias campañas de excavación en la localidad, entre las cuales es citada claramente la de Bergara, donde al parecer se hallaron algunas piedras talladas pertenecientes a indeterminadas construcciones de importancia (PARÍS y ENGEL, 1906). 
Que las referencias locales al hallazgo de "un brazo de bronce" y otras esculturas no eran inciertas es prueba palpable la magnitud de la parte de la villa excavada (unos 2.500 metros cuadrados), la entidad de los restos arquitectónicos -que en alguna estancia parecen un compendio de edilicia romana-, y sobre todo la calidad de los hallazgos escultóricos, pictóricos y musivos. Por otro lado, la certeza de que bajo los restos espléndidamente conservados de la villa bajoimperial del s. IV d.C. hay restos de estructuras anteriores, datables incluso en periodo julio- Claudio (s. I d.C.) añade valor a la información que la villa nos proporciona. Algunos de los trabajos que -a modo de avances- se presentan en este mismo volumen dan idea cabal de lo que aquí sintetizamos.

Por otro lado, ademas de la villa, y justo al norte de la misma, se han excavado un total de 140 sepulturas sobre un área de 1.600 metros cuadrados, correspondientes a una necrópolis de inhumación tardonomana -posiblemente visigoda-, cuyo estudio detallado, incluyendo análisis paleoantropológicos y la realización de una Memoria de Licenciatura se halla ya en curso.

\section{Limpieza en el "Cerro de las Cabezas"(Fuente Tójar)}

Durante el verano de 1989 se han llevado también a cabo obras de reacondicionamiento y limpieza de una pane de las estructuras visibles en el Cerro de las Cabezas, por encargo de la Dirección General de Bienes Culturales de la Junta de Andalucía a través de la Delegación de Córdoba de la Consejería de Cultura. Estas labores han estado subvencionadas por el INEM, con el apoyo del Ayuntamiento de Fuente Tójar, con vistas a una eventual declaración del yacimiento como Bien de Interés Cultural. Dichos trabajos se han efectuado bajo la supervisión de D. J.R. Carrillo y D. R. Hidalgo, miembros ambos del equipo que desarrolla nuestro Proyecto.

Ya hemos aludido repetidamente a lo largo de este artículo a la importancia que por múltiples razones debió tener este yacimiento. Entre ellas, cabe destacar su extensión (quince hectáreas, casi el triple que el Cerro de la Cruz); el volumen visible de sus fortificaciones; su posición estratégica en la salida norte de los tres valles formados por los ríos subbéticos hacia Baena y la Campiña; la larga ocupación del yacimiento, al menos desde el Bronce Final y quizá desde el Calcolítico y, por último, su carácter de municipio romano, probablemente Illiturgicola.

A pesar de las excavaciones efectuadas en las necrópolis de sus alrededores por distintos investigadores desde mediados del s. XIX (Maraver, Navascues, Marcos Pous, Vicent) el poblado propiamente dicho no ha sido excavado, y en cambio ha sufrido en repetidas ocasiones las depredaciones de los excavadores clandestinos.

El trabajo de 1989 se ha limitado a eliminar algunos majanos y limpiar la maleza que amenazaba con dañar parte de los imponentes lienzos de muralla y cubría una serie de estructuras excavadas total o parcialmente en la roca, estructuras de las que se ha levantado un primer plano topográfico. La zona afectada ha sido la Suroeste, zona de máxima altitud y donde la erosión ha sido más intensa. Entre las estructuras, destaca la documentación de unas veinte habitaciones con suelos y zócalos de muros tallados en la roca, así como umbrales y escaleras, además de agujeros de poste para vigas de madera. Estas habitaciones se disponen en varios niveles y sin duda corresponden a varias estructuras complejas. No es posible por ahora establecer como fue el alzado de los muros, al no haberse realizado excavación alguna. La recuperación de algunos fragmentos de estuco pintado y de ladrillos 
romanos de los utilizados para suelos sugieren una ocupación de época romana, lo que en modo alguno elimina la posibilidad de ocupaciones anteriores en esta zona del yacimiento.

Además, se han documentado tres grandes aljibes excavados en la roca, de planta ovalada. Uno de ellos conserva todavía parte de su cubierta a base de lajas de piedra, y del revestimiento de signinum que lo impermeabilizaba. Alrededor de ellos, y también excavados en la roca, se observan los canales que traían y evacuaban el agua. Además de las cisternas descritas, otras muchas se reparten por toda la superficie del yacimiento.

Por último, queremos señalar la existencia de una calle también excavada en la roca, en sentido perpendicular a la línea de muralla.

Durante el mismo periodo, se han efectuado trabajos de organización y sistematización de los fondos arqueológicos depositados en el Ayuntamiento de Fuente Tójar, con vistas a la creación del Museo Histórico Local, ya montado y pendiente sólo de su inauguración.

\section{Otras actuaciones}

Además de los trabajos de campo que acabamos de resumir, dentro del marco de nuestro Proyecto se han llevado a cabo otras actividades, entre las que podemos destacar:

a) Creación de una Escuela-Taller de Arqueología en Almedinilla, bajo la dirección de uno de nosotros (D. Vaquerizo), con fondos de la CEE, canalizados a través del INEM en su apartado "Ámbito Restauración". Esta Escuela-Taller, aparte de formar a alumnos jóvenes de la zona, ejerce una insustituible labor de apoyo en los trabajos tanto de campo como de gabinete. Asimismo, la presencia permanente durante el último año de un arqueólogo y un restaurador contratados ha permitido ejercer una continua labor de seguimiento de los yacimientos y de clasificación y catalogación de los materiales.

b) Por lo que se refiere a los resultados en el ámbito de la legislación, un primer resultado ha sido la declaración del Área Arqueológica del Cerro de la Cruz como Bien de Interés Cultural (BOJA, 97,18 de noviembre de 1987, pp. 5282-5283).

c) En lo que respecta al objetivo ' 'E'" (protección y conservación de los yacimientos), un primer logro ha sido el vallado de la zona central del poblado, actividad sufragada por la Delegación de Cultura de la Junta de Andalucía en Córdoba (expediente 1915, autorización de fecha 28 de septiembre de 1988), y realizada durante el mes de octubre del mismo año. Sin embargo dicho vallado -por otra parte bien sólido aunque no infranqueable- no ha detenido el continuado expolio por parte de excavadores clandestinos despechados, que tras las campañas de 1987 y 1989 han continuado sus depredaciones, realizando numerosos y profundos agujeros en los perfiles de los cortes y dañando intencionadamente algunas de las estructuras exhumadas. Para tratar de evitar estas actividades, en nuestro proyecto para 1990 se incluye el vallado definitivo del Cerro de la Cruz y la Villa del Ruedo, así como su cubrición y consolidación, que consideramos indispensables si se quiere garantizar su conservación, habida cuenta además, de la climatología de la comarca.

d) Compra de un edificio con vistas a la futura instalación del Museo Municipal Arqueológico y de Artes y Costumbres populares en Almedinilla. En concreto, se trata del denominado' 'Molino de Fuente Ribera", ubicado en la base de la ladera Noroeste del Cerro de la Cruz, en la misma vega del río Almedinilla, con una superficie aprovechable de 4.000 metros cuadrados. Conserva completos un molino de aceite con sus respectivos almacenes y accesorios, un molino harinero y la turbina a vapor que proporcionó la primera luz eléctrica a Almedinilla, por lo que si además tenemos en cuenta que su construcción data 
de principios del s. XIX, el siguiente paso habrá de ser igualmente de apertura de un expediente para su declaración como Bien de Interés Cultural.

Algunos problemas e hipótesis de trabajo

Para concluir este ya largo trabajo vamos a presentar algunos de los problemas y principales hipótesis de trabajo que pretendemos contrastar.

En un nivel alto de generalidad, quizá el principal problema planteado sea el del si esta zona pudo tener a lo largo del periodo estudiado un carácter marginal e incluso en determinados momentos claramente fronterizo. Ciertamente, y por lo que se refiere al periodo ibérico, la escasez de yacimientos en comparación con la zona del medio-alto Genil y con la campiña (MURILLO y otros, 1989) nos hace reflexionar de nuevo sobre la geografía de la comarca en relación con los dos principales yacimientos conocidos en el área de los ríos Almedinilla-San Juan, Mirando hacia el Norte desde el Cerro de las Cabezas de Fuente Tójar se domina una enorme extensión de abierta y relativamente llana Campiña; en cambio, si miramos hacia el Sur desde el Cerro de la Cruz de Almedinilla, relacionado visualmente con aquel, el terreno que se observa es bien distinto: escarpadas Sierras y estrechos pasos que nos llevan al Sistema Bélico y las Altiplanicies granadinas. El área entre el Cerro de las Cabezas y el de la Cruz es una zona de transición geográfica entre dos áreas distintas, y quizá lo fue también desde el punto de vista cultural e incluso político durante el periodo ibérico, habida cuenta de que este relativo vacío de poblamiento se observa también en Jaén al Sur del río Víboras \{MONT1LLA y otros, 1989) (nos resistimos a utilizar el término "Black Hole", tomado de la Astrofísica, que además indica justamente lo contrario de lo que se pretende decir: una concentración tal de materia de tan enorme densidad que ni siquiera la luz escapa a su atracción gravitatoria). Sin embargo, en periodos anteriores y posteriores al Ibérico Pleno no se aprecia este fenómenocon la misma claridad: ya hemos hablado de la importancia que pudo tener durante el Bronce Final la ruta que desde el Genil pasaba por Carcabuey y subía por el Zagrilla hasta Fuente Tójar y la Campiña; y también se aprecia en nuestra prospección de 1989 una mayor densidad de poblamiento en Baja Época Ibérica (en lo que de nuevo vienen a coincidir los investigadores de Jaén, MONTILLA y otros, 1989:146).

Durante e) Bronce Final y Orientalizante conocemos en la Subbética un número muy reducido de yacimientos: Cerro del Castillo de Carcabuey (MURILLO y RUIZLARA e.p.; VAQUERIZO, 1983-84; HARRISON, 1974-75); Camino del Tarajal sobre el Salado, ya cerca de la desembocadura (VAQUERIZO, 1987:17-18; GAVILÁN, 1987:93-94; BERNIERy otros, 1981:79 ss.); La Almanzora (denominada Cerro de la Amazona en el mapa topográfico 1:50.000) (VAQUERIZO, 1987:16; FORTEA y BERNIER, 1970:52); y Cerro del Puerto en Las Lagunillas (VAQUERIZO, 1987:16-17). La prospección realizada por nosotros este año en la zona del Almedinilla-San Juan sólo nos ha dado a conocer un nuevo yacimiento con materiales del Bronce Final, el Cerro de las Cabezas de Fuente Tójar, aunque en algún otro punto han aparecido escasos fragmentos a mano no significativos que pudieran eventualmente datarse en esta etapa.

La situación actual de nuestro conocimiento sobre el Bronce Final y periodo Orientalizante en la zona puede resumirse, en esencia, en tres puntos: conocemos sólo grandes yacimientos aislados, sin excavaciones y sin relación directa entre sí; dichos yacimientos se 
encuentran sobre las vías más importantes de la zona, las que pudieron comunicar el Genil con la Campiña: el Cerro del Castillo de Carcabuey y el Cerro del Puerto en las rutas del Sur y La Almanzora, Camino del Tarajal y Cerro de las Cabezas hacia el Norte. En tercer lugar, en la zona prospectada con mayor intensidad (la oriental) no han aparecido apenas nuevos yacimientos. Todo ello parece apuntar a una escasez y concentración del hábitat, que a lo largo del s. VII al menos parecería orientarse en el eje Benamejí-Carcabuey-desembocadura del Salado (puntas de flecha de arpón; espada y urna de Carcabuey, etc.). Habría que comprobar la existencia de más yacimientos en esa vía e insistir en las prospecciones sistemáticas.

Por lo que se refiere a la época ibérica (hasta ahora el período en que más hemos incidido), la cantidad de problemas planteados y de hipótesis de cierto alcance formuladas es mucho mayor.

En primer lugar está la posibilidad de que la zona fuera en los siglos V-IV un área de frontera política, con un poblamiento polarizado en tomo a dos yacimientos principales en la cuenca del Almedinilla-San Juan (todavía no conocemos lo suficiente el panorama en la zona del Salado-Zagrilla). En tal caso, habría que definir si el imponente Cerro de las Cabezas controlaba el asentamiento menor del Cerro de la Cruz (todo ello controlando los pasos que venían desde el Sur), o si por el contrario ambos yacimientos se alineaban en estructuras políticas distintas y potencialmente hostiles.

Uno de los aspectos previos para contestar ésta pregunta sería estudiar cuidadosamente la cultura material del Cerro de la Cruz, para comprobar si -como nos parece en una primera hipótesis- los paralelos en este sentido relacionan el yacimiento con el mundo granadino y en última instancia con el Sureste peninsular, o si está más relacionado con el mundo de la Baja Andalucía y el Valle del Bajo Guadalquivir.

En segundo lugar se hace imprescindible comprobar si la aparente ausencia de yacimientos eh llano y vega es real o efecto de una prospección engañosa por múltiples factores- (erosión, destrucción por cultivos, sepultamiento profundo bajo aluviones, muestreo defectuoso, etc.).

Sería necesario también hallar una explicación para la ausencia casi completa de recintos fortificados, tan frecuentes justo al Norte de la zona que estudiamos, y tratar de completar modelos para los tipos de control y explotación económica del territorio, así como contrastar la hipótesis de Fortea-Bemier de que estos recintos controlarían la importante vía que deja la Sierra de Cabra por el Sur y pasa por la zona de Baena-CabraPuente Genil. lo que en principio podría explicar aquel hecho, pero a la vez convertiría la Subbética en un área decididamente marginal, lo que no parece encajar con la riqueza de los materiales de la necrópolis de Los Collados ni con la entidad del Cerro de las Cabezas de Fuente Tójar.

Otro aspecto a estudiares la base económica, indudablemente agropecuaria, por encima del comerció o la minería. Sin embargo, se hace necesario precisar más: importancia de los cultivos de vega; áreas susceptibles de cultivos de secano con rendimientos adecuados; primacía o no del ganado ovicaprino y posible importancia de la cabaña; posibilidades de la caza mayor (cérvidos, a partir de los primeros da tos ya citados del estudio arqueozoológico de los huesos de la campaña de 1985 en el Cerro de la Cruz).

Por lo que se refiere a las excavaciones del Cerro de la Cruz, tenemos todavía más problemas que soluciones. Resaltaremos ahora algunos de aquellos.

- Resulta extraña la aparente ausencia de fortificaciones: es probable que existieran pero 
estén muy arrasadas: eso debe ser probado arqueológicamente.

- En una sociedad de Jefatura lindando ya con lo estatal -si no propiamente estatal como proponen algunos- uno de los requisitos que se suele considerar es que en los poblados haya zonas residenciales separadas, o al menos manifestaciones materiales de las diferencias de estatus en forma de edificios más suntuosos y grandes. De la misma forma, debe suponerse la existencia de espacios de uso público más complejos que la calle. En el Cerro de la Cruz, pese a la superficie excavada, todavía no ha sido posible documentar esto. En realidad, ya hemos aludido al problema que supone precisar la funcionalidad de muchas de las estancias excavadas, que por su disposición y tamaño pudieran considerarse viviendas, pero cuyos materiales parecen apuntar más bien hacia almacenes o centros de procesado de grano, talleres artesanos, etc.

- También es un problema el de la cronología documentada para el poblado: el margen de utilización de las estructuras excavadas parece ir desde mediados del s. III hasta un abandono en la segunda mitad del s. II a.C. Sin embargo, algunos -muy escasos- materiales de superñcie apuntan a la existencia de un poblado anterior, de principios del s. IV a.C, del cual todavía no ha sido posible documentar con seguridad estructura alguna. Es más que probable que el poblado antiguo se ubicara en la parte más alta del Cerro, hoy erosionada por completo, y en otros puntos completamente removida por trincheras excavadas durante la Guerra Civil. En cualquier caso, tenemos una necrópolis -la de Los Collados- cuyos materiales, entre los que no hay material importado, han sido fechados siempre en tomo al s. IV a.C. Quizá debamos revisar a la baja esta datación a la vista de los resultados obtenidos en el poblado -lo que remueve el problema de la pervivencia de determinados tipos antiguos en contextos funerarios-.

- Constituiría un éxito el poder identificar la causa -accidental o no- de la destrucción violenta por incendio de toda la pane del poblado que ya hemos excavado, para lo cual sería necesario previamente determinar si toda o casi toda la superficie del asentamiento corrió la misma suerte. El que no se revolvieran los restos tras el incendio para recuperar lo posible, y el que no se reedificaran las estructuras parece apuntar hacia una destrucción intencionada de la que todavía no podemos señalar responsables.

- En un ámbito más reducido, es problemática la coexistencia de estructuras de carácter helenístico avanzado (como por ejemplo aljibes ovales con un revestimiento hidráulico, cubienos con lajas de piedra y rebosaderos de plomo; o molinos de tipo complejo) con materiales cerámicos en los que lo romano brilla por su ausencia (salvo un posible borde de ánfora Dressel I y algunas monedas republicanas de bronce del tipo Jano-proa).

- Un problema que parece común a todo el área de la Subbética es la gran escasez de material griego, como por ejemplo se aprecia en la propia necrópolis de Los Collados, aspecto que todavía no se ha explicado satisfactoriamente.

- Para terminar esta enumeración, aludiremos también a la presencia masiva de armas en los ajuares de la necrópolis, con tipologías muy próximas a las de yacimientos granadinos (Tózar, Illora), en una zona no especialmente notable por yacimientos de hierro. No olvidemos, en este sentido, que Almedinilla es la necrópolis más occidental en la que se hayan documentado armas. Más hacia el Oeste entramos en una Turdetania en la que las necrópolis brillan por su ausencia (ESCACENA, 1987:295-297).

Por lo que se refiere al mundo romano, un primer problema es el planteado por la transición de esa cultura propiamente ibérica a otra iberorromana en la que el impacto romanizador pleno parece haberse dilatado mucho en el tiempo (en pleno siglo II el Cerro 
de la Cruz todavía no puede denominarse "iberorromano" al menos en su cultura material, e incluso en zonas de Campiña mucho más próximas al Guadalquivir la romanización es superficial y tardía, MUÑOZ AMILIBIA, 1987:68). Por un lado, habría que confirmar la aparente mayor densidad del poblamiento en Baja Época Ibérica, acompañada de una mayor dispersión (aspecto todavía dudoso habida cuenta de que los materiales ibéricos recogidos, en su mayoría asociados a otros romanos, proceden de prospección superficial),

Por otro lado, en la zona de Almedinilla al menos -no parece que en la zona del Cerro de las Cabezas exista solución de continuidad- hay que rellenar el hiato existente entre el abandono del Cerro de la Cruz y el comienzo de la ocupación de la cercana villade El Ruedo, de época Julio-Claudia.

Parece evidente que el poblamiento rural romano altoimperial en la zona se articula sobre villae de llano, ubicadas junto a la vega en función del abastecimiento de aguas, pero no sabemos todavía casi nada de su régimen económico (tipos de cultivos y de explotación, etc.), salvo los restos -todavía no estudiados- de la pars rustica de la villa de El Ruedo, paradigma de las restantes de la zona y posiblemente su más espectacular exponente.

La villa de EI Ruedo proporciona además taposibilidad de estudiar en detalle la continua remodelación de estructuras desde principios de la Era cristiana hasta un máximo de esplendor arquitectónico a principios del s. IV d.C. para luego comenzar una lenta decadencia visible en el reaprovechamiento de elementos edilicios para menesteres cada vez más pobres (columnas reutilizadas para construir un modesto horno, etc.). De la misma forma, sus conjuntos de pintura mural, musivarios, etc. pueden calificarse de excepcionales.

Por otro lado, el hallazgo del magnífico conjunto de esculturas que se presenta en otro artículo no sólo incita a un obligatorio análisis estilístico, sino a una profunda reflexión sobre la capacidad adquisitiva de los señores rurales y a su capacidad de refinamiento incluso en épocas muy avanzadas en que la vida urbana se va desintegrando. Del posible papel rector de Iliurgicola -aceptando que el Cerro de las Cabezas tuviera tal nombre- en todo el contexto de la Subbética nada sabemos todavía.

Por último, el estudio minucioso, tanto arqueológico como antropológico, de la necrópolis tardorromana de El Ruedo puede proporcionamos información de sumo interés en todos o muchos de los aspectos actualmente enfatizados por la "Arqueología de la Muerte".

Sirvan los párrafos anteriores como enunciado breve pero representativo de la cantidad y calidad de preguntas que en este momento nos hacemos y para cuya clarificación -dentro de lo posible- trabajamos. Hay por ahora muchas más incógnitas que respuestas y, lo que es peor, cada avance nos lleva a plantearnos nuevos interrogantes. En realidad, sin embargo, esto es lo que cabía esperar, y la continua evolución de nuestros planteamientos está en la base de una investigación que ante todo pretende ser honesta.

Asumiente el riesgo de omitir involuntariamente algún nombre, queremos agradecer públicamente su ayuda en los más diversos campos a las siguientes personas y entidades: Consejería de Cultura de la Junta de Andalucía, Delegación de Cultura en Córdoba; Delegación de Obras Públicas; Excmo. Ayuntamiento de Almedinilla; Excmo. Ayuntamiento de Fuente Tójar; O.C.I.S.A.; I.N.E.M.; así como a todos los licenciados, estudiantes, alumnos del Curso de Restauración y obreros que han trabajado con nosotros durante los últimos años. 


\section{Bibliografía}

ABAD CASAL, L. (1987) "La cultura ibérica". Historia General de España y América, 12, Madrid, RIALP, 171-223.

AGUAYO DE HOYOS, P.; SALVATIERRA CUENCA, V. (1987) "El poblamiento ibérico en las altiplanicies granadinas". Iberos, Jaén, 1985. 229-238.

ALCINA FRANCH, J. (1975) En torno a la Antropología Cultural, Madrid.

ALEKSHIN, VA. (1983) "Burial Customs as an archaeologjcal Source", Current Anthropology,24,2,137-149.

ALMAGRO BASCH. M. (1960) Introducción al estudio de la Prehistoria y de la Arqueología de campo, Madrid.

ARRIBAS, A. (1965) Los Iberos, Barcelona.

ARTEAGA, O. (1985) "Excavaciones arqueológicas sistemáticas en el Cerro de los Alcores (Porcuna, Jaén). Informe Preliminar sobre la campaña de 1985". A A A.. 1.2,279288.

ARTEAGA, O.; BLECH, M. (1987) "La romanización en la zonas de Porcuna y Mengíbar (Jaén)", Los asentamientos ibéricos ante la romanización, Madrid, febrero 1986, 89-99.

ASQUERJNO, M.D. (1985a) "Sepultura argárica en Priego de Córdoba", B.RA.C, 109,183-187.

ASQUERINO, M.D. (1985b) "La campaña de excavaciones de 1985 en la Cueva de los Mármoles (Priego de Córdoba)". A A A., 1.2, 226.

ASQUERINO, M.D. (1986) "Estructura de acondicionamiento en la "Cueva de los Mánnoles" (Priego de Córdoba)" Arqueología Espacial. Coloquio sobre el microespacio, 8,103-114.

BARKER, P, (1977) Techniques of Archaeological excavation, Londres.

BENDALA GALÁN, M. (1981) "La etapa final de la cultura ibero-turdetana y el impacto romanizador". La Baja Época de la Cultura Ibérica, Madrid, marzo 1979, 33-50.

BERNIER, J. et alii (1981) Nuevos yacimientos arqueológicos en Córdoba y Jaén, Córdoba.

BINFORD, L.R. (1988) En busca del pasado, Barcelona (ed.or. 1983).

BLANCO FREIJEIRO, A.; LUZON NOGUE, J.M.; RU1Z MATA, D. (1969) "Panorama tartésico en Andalucía Oriental", V Symposium de Prehistoria Peninsular. Tartessos y sus problemas, Jerez, 1968. Barcelona.

BLAZQUEZ, J.M. (1981) "El mundo ibérico en los siglos inmediatos al cambio de Era", La Baja Época de la cultura Ibérica, 17-29.

BLAZQUEZ,J.M.;GARCIAGELABERT,M.P.(1987)"El final del mundoibérico en la

Bélica", Iberos. Jaén. 1986,349-361.

BROTHWELL, D.; HIGGS E. (1980) Ciencia en Arqueología, Méjico (ed.orig. 1963).

BROTHWELL, D.R. (1987) Desenterrando huesos. Méjico.

BURJLLO MOZOTA, F. (1980) El Valle Medio del Ebro en Época Ibérica, Zaragoza.

BURJLLO MOZOTA, F. (1984)' 'La aplicación de los modelos del Lugar Central a la Arqueología", las. Jornadas de Metodol. de Investigación Prehistórica, Soria, 1981,431441.

BURRLO MOZOTA, F. et alü (1984) "Un estudio sincrónico y diacrónico del poblamiento y el territorio: El proyecto interdisciplinar de Mora de Rubielos (Teruel)", 
Arqueología Espacial, 1,187-205.

BURILLO MOZOTA, R; SUS GIMÉNEZ, M.L. (1986) "Estudio microespacial de la casa 2 del poblado de época ibérica "Los Castellares*' de Herrera de los Navarros (Aragón)", Arqueología Espacial, 9,209-236.

CARRASCO RUS, i.etalii (1985) "Informe preliminar de la campaña de excavaciones de 1985 en el Cerro de la Mora (Moraleja de Zafayona, Granada)", Anuario Arqueológico de Andalucía, 1985, tomo II, 266-272.

CARRILLO, J.R.; HIDALGO, R. (1989, e.p.) "El yacimiento arqueológico del Cerro de las Cabezas (Fuente Tójar, Córdoba)", XX C.NA., Santander.

CASTRO LÓPEZ, M. (1986) "Consideraciones preliminares para la reconstrucción de la Etapa Romana en el Alto Guadalquivir: Una perspectiva arqueológica". Arqueología en Jaén..., 69-74.

CERRILLO MARTIN DE CACERES, E. (1984) "Problemas en el conocimiento. El ruido en la información arqueológica", las. Jornadas de Metodol. de Investigación Prehistórica, Soria. 1981, 65-69.

CLARK, G. (1980) Arqueología y Sociedad, Mardid (ed.or. 1939).

CLARKE, D.L. (1973) "Archaeology: fheloss of \nocenaz $\backslash$ Antiquity 57, 6-18.

CLARKE, D.L. (1984) Arqueología Analítica, Barcelona (ed.or. 1968).

CONTRERAS CORTES, F. (1984) "Clasificación y Tipología en Arqueología. El camino hacia la Cuantificación", C.P.U.G., 9, 327-385.

CRESPO GARCÍA, J.M.; LÓPEZ ROZAS, J. (1984) "Algunas cuestiones sobre los modelos de asentamiento ibérico en la cuenca alta del río Víboras. Manos, Jaén". Arqueología Espacial, 4, 207-222.

CUADRADO DÍAZ, E. (1981) "Las necrópolis peninsulares en la Baja Época de la Cultura Ibérica", La Baja Época de la Cultura Ibérica, Madrid 1979. 51-69.

CUNLIFFE.B.; FERNANDEZ CASTRO, M.C. (1988) "Torreparedones (Castro del Rfo-Baena, Córdoba)". Jornadas de Arqueología Andaluza, Sevilla.

CHANG, K.C. (1976) Nuevas perspectivas en arqueología, Madrid (ed.or, 1967).

CHAPA BRUNET, T. (1980) Laescultura zoomorfa ibérica en piedra. Tesis Doctorales Universidad Complutense de Madrid.

CHAPA BRUNET, T. (1988) "Perspectivas actuales de la arqueología española", Revista de Occidente, 81. 135-142,

CHAPA BRUNET, T. (1989) Recensión de HARRISON (1988) en Trabajos de Prehistoria, 46,1989, 341 -343.

CHAPA BRUNET. T.; FERNANDEZ. M.; PEREIRA, J.; RUIZ, A. (1984) "Análisis económico y territorial de los Castellones de Ceal (Jaén)", Arqueología Espacial, 4, 223 240.

CHAPA BRUNET, T.; PEREIRA, J. (1986) "La organización de una tumba ibérica: un ejemplo de la necrópolis de los Castellones de Ceal (Jaén)** Arqueología Espacial. Coloquio sobre el Microespacio, 9,369-386.

CHAPA BRUNET, T; RUIZ RODRÍGUEZ, A.; PEREIRA SIESO. J. (1985) "Excavaciones en el yacimiento ibérico de Los Castellanos de Ceal (Hinojares, Jaén). Campaña de 1985". AAA., 1.2, 353-356.

CHAPMAN, R.; KINNES, L; RANDSBORG. K. (eds.) (1981) The Archaeology of Death, Cambridge.

CHOCLAN SABINA, C; HORNOS, F.; MOLINOS, M.; RUIZ RODRÍGUEZ, A. 
(1984) "Bases fundamentales para la elaboración de un modelo de ficha para la prospección sistemática", Arqueología Espacial, 1, 149-165.

ENGUIX ALEMANY. R. (1973) "Aproximación a una historia de la investigación de la Cultura Ibérica'*. Saguntum, 9,19-28.

ESCACENA CARRASCO, JL. (1987) "El poblamiento ibérico en el Bajo Guadalquivir", Iberos..., 273-298.

ESTEVEZ, J. et alii (1984) "Arqueología como Arqueología. Propuestas para una terminología operativa", jas. Jornadas de Metodol. de Investigación Prehistórica, Soria, 1981,21-28.

FERNANDEZ MARTÍNEZ, V. (1985) "La sedación automática en Arqueología: Introducción Histórica y aplicaciones"; T.P., 42, 9-49.

FERNANDEZ MARTÍNEZ, V. (1989) Teoría y Método de la Arqueología, Madrid.

FERNANDEZ MIRANDA, M. (1984) "Arqueología Prehistórica y estructura científica", jas. Jornadas de Metodol. de Investigación Prehistórica, Soria, 1981, 11-20.

FERNANDEZ MIRANDA, M. (1988) "'Entre la antropología y la Historia". Revista de Occidente, 81, Febrero 1988. 5-14.

FORTEA, J.; BERNIER, J. (1970) Recintos y fortificaciones ibéricas en la Bélica, Salamanca.

GAVILÁN CEBALLOS. B. (1984) "La cueva de la Murcielaguina de Priego (Córdoba): análisis de un asentamiento neolítico", Arqueología Espacial, 3, 17-30.

GAVILÁN CEBALloS, B. (1987) Los materiales de la Prehistoria en Priego de Córdoba, Córdoba.

GIMENO V1GUERA, I.; GONZÁLEZ BRAVO, R.; QUESADA SANZ. F. (1988) "Arqueólogos Informálica.",Boletín Asoc. Española de Amigos de la Arqueología, 24,517.

HARRIS. E.C. (1979) Principies of Archaeological Stratigraphy, Londres.

HARRISON, R.J. (1974-75) "Notas acerca de algunas espadas del Bronce Final en la Península Ibérica" Ampurias, 36-37,225-226.

HARRISON, R.J. (1988) Spain at the dawn of History. Iberians, Phoenicians and Greeks, Londres.

HODDER, I. (1988) interpretación en Arqueología. Corrientes Actuales, Barcelona (ed.or. 1986).

HODDER. I.; ORTON.C. (1976) Spatial Analysis in Archaeology. Cambridge.

HOLE, F.; HEIZER. R.F. (1977) Introducción a la arqueología prehistórica, Méjico (ed.or. 1965).

LÓPEZ PALOMO. L. A. (1980) La Cultura Ibérica del Valle Medio del Genil, Córdoba.

LÓPEZ PALOMO, L.A. (1983) "Testimonios de la iberización al Sur de Córdoba y Sevilla" CAÁ., XVI, Murcia-Cartagena 1982, 795-804.

LULL, V. (1983) ¿a "Cultura" de ElArgar, Madrid.

LUZON, J.M.; RUIZ MATA, D. (1973) Las raíces de Córdoba. Estratigrafía de la Colina de los Quemados, Córdoba.

LLOBREGAT CONESA, E. (1972) Contestania ibérica, Alicante.

MARCOS POUS, A.; VICENT, A.M. (1983) "La necrópolis ibericoturdetana de Los Torviscales, Fuente Tójar", Novedades de Arqueología Cordobesa. Exposición Bellas Artes 83, Córdoba.

MARAVER y ALFARO, L. (1867a) "Descubrimientos arqueológicos en Almedinilla", 
Revista de Bellas Artes e Histérico-Arqueológica, 2- serie, 2, 9.

MARAVER y ALFARO, L. (1867b) "Expedición arqueológica en Almedinilla" Revista de Bellas Artes e Histérico-Arqueológica, $2^{\mathrm{a}}$ serie, 2, 307-323.

MARTIN DE GUZMAN, C. (1984) "Nociones epistemológicas y arqueología prehistórica", las. Jornadas de Metodol. de Investigación Prehistórica, Soria, 1981, 35-64.

MARTIN DE LA CRUZ, J.C. (1985) "La campaña de 1985 en el Llanete de los Moros, Palomarejo (Montoro, Córdoba)", AAA. 1.2, 313-318.

MARTIN DE LA CRUZ, J.C. (1987) "El Llanete de los Moros (Montoro, Córdoba)", EA.E., 151 .

MARTÍNEZ NAVARRETE, M.I. (1989) "Una revisión crítica de la Prehistoria española: la Edad del Bronce como paradigma", Madrid.

MELCHOR, E. (1987) La red de comunicaciones romana en la provincia de Córdoba, Memoria de Licenciatura Inédita, Universidad de Córdoba.

MONTILLA.S.; RISQUEZ.C; SERRANO, J.L.; COBA, B.E. (1989) "Análisisde una frontera durante el horizonte ibérico en la depresión Priego-Alcau de te". Arqueología Espacial. Fronteras, 13,137-150.

MORENA LÓPEZ, J.A. (1989) El Santuario ibérico de Torreparedones, Castro del Río-Baena, Córdoba, Córdoba.

MORENA LÓPEZ, JA.; SÁNCHEZ, M.; SERRANO, J.; GARCÍA FERRER, A. (1987) Contribución a la carta Arqueológica de la Provincia de Jaén, Córdoba.

MUÑOZ AMILIBIA, A.M. (1987) "Un ejemplo de continuidad del tipo de vivienda ibérica en el Municipio de Iponuba. El Cerro del Minguillar (Baena, Córdoba)" Los asentamientos ibéricos ante la romanización, Madrid, febrero 1986, 63-68.

MURTLLO REDONDO, J.F. (1988 e.p.) "Poblamiento prehistórico y minería en el Norte de la Provincia de Córdoba", ¡Coloquio de Historia Antigua de Andalucía, Córdoba.

MURILLO, J.F.; QUESADA, F.; VAQUERIZO, D.; CARRILLO, J.R.; MORENA, JA. (1989)' 'Aproximación al estudio del poblamiento protohistórico en el Sureste de Córdoba: unidades políticas, control del territorio y fronteras". Arqueología Espacial. Fronteras, 13, 151-172.

MURILlO REDONDO, J.F.; RUIZ LARA, D. (e.p.) "El Cerro del Castillo de Carcabuey. Un yacimiento del Bronce Final-Orientalizante en las Subbéticas Cordobesas" Primera Reunión de Estudios de Historia Local, Córdoba.

NAVASCUES, J.M. (1934) "Sucaelo", Anuario del Cuerpo Facultativo de Archiveros, Bibliotecarios y Arqueólogos, I, 319-338.

NOCETE CALVO, F. (1984) "Jefaturas y territorio: una visión crítica", C.P.U.G., 9, 289-304.

ORTEGA ALBA, F. (1985) El Sur de Córdoba. Estudio de Geografía Agraria, Córdoba.

ORTON, C. (1988) Matemáticas en Arqueología, Madrid (ed.or. 1980)

PACHÓN ROMERO, J.A.; CARRASCO RUS, J.; MASTOR MUÑOZ, M. (1979) "Protohistoria de la Cuenca Alta del Genil", C.P.U.G., 4,295-340.

PAGE DEL POZO, V. (1984) "Imitaciones de influjo griego en la cerámica ibérica de Valencia, Alicante y Murcia". Iberia Graeca. Serie Arqueológica, 1, Madrid.

PARÍS, P.; ENGEL, A. (1906) "Fouilles et recherches á Almedinilla (Province Cordoue), Revue Archéologique, VIII, 49-92.

PEREIRA SIESO, J. (1987) "Necrópolis ibéricas de la Alta Andalucía", Iberos, Jaén $1985,257-272$. 
PEREIR A SIESO, J. (1988) La cerámica pintada a torno en Andalucía entre ios siglos VI y III a.C. Cuenca del Guadalquivir. Tesis Doctorales Universidad Complutense de Madrid.

PRICE, N.P.S. (ed.) (1984) La Conservación en Excavaciones Arqueológicas, ICCROM, Roma.

PRIETO VAZQUEZ,G. (1987) "Sobreel método Harris de excavación arqueológica", Carpetania, 1,145-155.

QUESADA SANZ, F. (1989a) "Armamento, Guerra y Sociedad en la Necrópolis Ibérica de 'El Cabecico del Tesoro* (Murcia, España)", BA.R. International Series, 502, 2 vols. Oxford.

QUESADA SANZ, F. (1989b) "Informática en Arqueología: un ejemplo aplicado al estudio de jerarquización en necrópolis ibéricas", Boletín de la Asociación Española de Amigos de la Arqueología, 27, 36-44,

QUESADA SANZ, F. (1989c) "La utilización del arco y las flechas en La Cultura Ibérica", T.P., 46,161-201.

RAMÍREZ DE ARELLANO, R. (1904), Inventario Monumental y Artístico de la provincia de Córdoba, Ed. Facsímil 1983.

RAMOS FERNANDEZ, R. (1977) Arqueología, métodos y técnicas, Barcelona.

RENFREW, C. (1986) El alba de la Civilización, Madrid (ed.orig. 1973).

RICHARDS, J.D.; RYAN.N.S. (1985) Data Processing in Archaeology, Cambridge.

ROCA, M.; NOCETE, F.; PÉREZ, C; LIZCANO, R.; ZAFRA, N. (1985) "Prospección de la Vega del Guadalquivir de acuerdo con el Proyecto de investigación sobre el Centro de producción de Terra Sigillata de los Villares de Andújar (Jaén) y su difusión, 1985" AA.A., 1.2, 51-54.

ROCA, M.; NOCETE, F.; LIZCANO, R.; ZAFRA, N.; PÉREZ, C (1987) "Aportaciones al proceso de romanización en el Alto Guadalquivir" Jornades Intemacionals d'arqueología romana", Granollers, Febrero 1987,502-509.

RODRÍGUEZ NEILA, J.F. (1985) "Córdoba Hispano-Romana", en Córdoba y su provincia, II, Sevilla, pp. 101-204.

RUIZ RODRÍGUEZ, A. (1978) "Los pueblos iberos del Alto Guadalquivir. Análisis de un proceso de transición"; C.P.U.G., 3, 255-284.

RUIZ RODRÍGUEZ, A. (1987) "Ciudad y territorio en el poblamiento ibérico del Alto Guadalquivir", Los asentamientos ibéricos ante la Romanización, Madrid, Casa de Velázquez, Febrero 1986.

RUIZ RODRÍGUEZ, A.; CHAPA BRUNET, T.; RUIZ ZAPATERO, G. (1988) "La Arqueología Contextual: una revisión crítica", T.P., 45, 11-17.

RUIZ RODRÍGUEZ, A.; MOLINOS MOLINOS, M. (1984a) "Poblamiento ibérico de la Campiña de Jaén. Análisis de una ordenación del territorio". Primeras Jornadas de Metodología de Investigación prehistórica. Soria, 1981, Madrid, 421-429.

RUIZ RODRÍGUEZ, A.; MOLINOS MOLINOS, M. (1984b) "Elementos para un estudio del patrón de asentamiento en las campiñas' del Alto Guadalquivir durante el Horizonte Pleno Ibérico (un caso de sociedad agrícola con Estado)". Arqueología Espacial, 4,187-206.

RUIZ RODRÍGUEZ, A.; MOLINOS MOLINOS, M. (1989) "Fronteras: un caso del siglo VI a.n.e.". Arqueología Espacial. Fronteras", 13, 121-136.

RUIZ RODRÍGUEZ. A.; MOLINOS MOLINOS, M.; HORNOS MATA, F. (1986a) 
Arqueología en Jaén (Reflexiones desde un proyecto arqueológico no inocente), Jaén.

RUIZ RODRÍGUEZ, A.; MOLINOS MOLINOS, M.; HORNOS MATA, F. (1986b)

"Perspectivas para la investigación del proceso histórico ibero en el Alto Guadalquivir", Arqueología en Jaén (Reflexiones desde un proyecto arqueológico no inocente), 75-81.

RUIZ RODRÍGUEZ, MOLINOS, M.; HORNOS, F.; CHOCLAN, C. (1987) "El poblamiento ibérico en el Alto Guadalquivir", íberos, Jaén, 239-256,

RUIZ ZAPATERO, G. (1987) "La recensión de publicaciones arqueológicas: S.O.S.", Trabajos de Prehistoria, 44,313-321,

RUIZ ZAPATERO, G. (1989) "Centro y periferia: la Europa Bárbara y el Mediterráneo en la Edad del Hierro", Trabajos de Prehistoria, 46, 331 -341.

SÁNCHEZ SASTRE, J. (coordinador) (1983) "Excavaciones clandestinas en el Cerro de la Cruz, Almedinilla", Revista de Arqueología, 32,48-49.

SEGURA ARISTA, L. (1988) La ciudad ibero-romana de Igabrum (Cabra, Córdoba), Dip. Prov. Córdoba.

SERRANO, J.; MORENA, J.A. (1984) Arqueología inédita de Córdoba y Jaén, Córdoba.

SERRANO, J.; PICO, M.T. (1988) "Las Roblizas, una fortificación inédita de Baena, Córdoba", Boletín Asoc. Española Amigos de la Arqueología, 24,25-26.

STYLOW, A. von (1983) "Inscripciones latinas del Sur de la Provincia de Córdoba", Gerión, I.

TARRADELL, M; SANMARTI, E. (1980) "L'etat actuel des études sur la ceramique ibérique" Annales Littéraires de l'Universíté de Besancon, 36, Paris.

TRIGGER, B. (1974)' 'The Archaeology of government", World Archaeology, 6.1,95105.

TRIGGER, B. (1982) La revolución arqueológica. El pensamiento de Gordon Childe, Barcelona (ed.orig. 1980).

UROZ SAEZ, J. (1981) La Regio Edetania en la época ibérica, Alicante.

VAQUERIZO, D. (1983-84) "Material ibérico del Museo de Priego", Corduba Archaeologica, 14,13-25.

VAQUERIZO, D. (1985a) "Excavación sistemática del Cerro de la Cruz (Almedinilla, Córdoba). Campaña de 1985", Anuario Arqueológico de Andalucía, vol. I.II, 319-322.

VAQUERIZO, D. (1985b) "La cueva de la Murcielaguina en Priego de Córdoba, posible cueva-santuario ibérico", Luentum, IV, 115-124,

VAQUERIZO, D. (1986a) "La muerte en el mundo ibérico cordobés: la necrópolis de Los Torviscales", Revista de Arqueología, 63, 41 ss.

VAQUERIZO, D. (1986b) "Ajuar de una tumba indígena, procedente de la necrópolis de Los Villalones, en Fuente Tójar, Córdoba", Arqueología Espacial. Coloquio sobre el microespacio, 9,349-369,

VAQUERIZO, D, (1987) "Aproximación a la Arqueología en la Subbética Cordobesa", Rev. de Arqueología, 11, 10-19.

VAQUERIZO, D. (1988a) Aproximación al fenómeno de la Cultura Ibérica en el SE de la actual Provincia de Córdoba. El yacimiento del Cerro de la Cruz (Almedinilla). Tesis Doctoral en Microficha, Universidad de Córdoba.

VAQUERIZO, D. (1988b) "Las necrópolis ibéricas de Almedinilla (Córdoba). Su interpretación en el marco sociocultural de la antigua Bastetania". ler Coloquio de Historia Antigua de Andalucía, Córdoba, Abril 1988 (en prensa). 
VAQUERIZO, D. (1988c) "Nuevas actividades arqueológicas en Almedinilla", Revista de Arqueología, Marzo 1990.

VAQUERIZO, D. (1990a) El yacimiento ibérico del Cerro de la Cruz (Almedinilla. Córdoba). Avance a su excavación arqueológica sistemática, Córdoba.

VAQUERIZO, D. (1990b) "La villa y necrópolis romanas de El Ruedo (Almedinilla, Córdoba)", Revista de Arqueología, Marzo 1990.

VICENT GARCÍA, J.M. (1983) "¿Es la Arqueología una ciencia?" Rev. de Arqueología, 32,62-64.

VICENT GARCÍA, J.M. (1984) "Fundamentos para una investigación epistemológica sobre la Prehistoria", las. Jornadas de Metodol. de Investigación Prehistórica, Soria, 1981, 71-87.

VICENT ZARAGOZA, A.M. (1984-85) "Trabajos arqueológicos inéditos en Fuente Tójar (Córdoba) de L. Maraver en 1867", Corduba Archaeologica, 15.

WATSON, P.J.; LeBLANC, S.A.; REDMAN, C.L. (1974) El método científico en arqueología, Madrid, 1974 (ed.or. 1971).

WHEELER, M. (1961) Arqueología de campo. Madrid (ed.orig. 1954). 


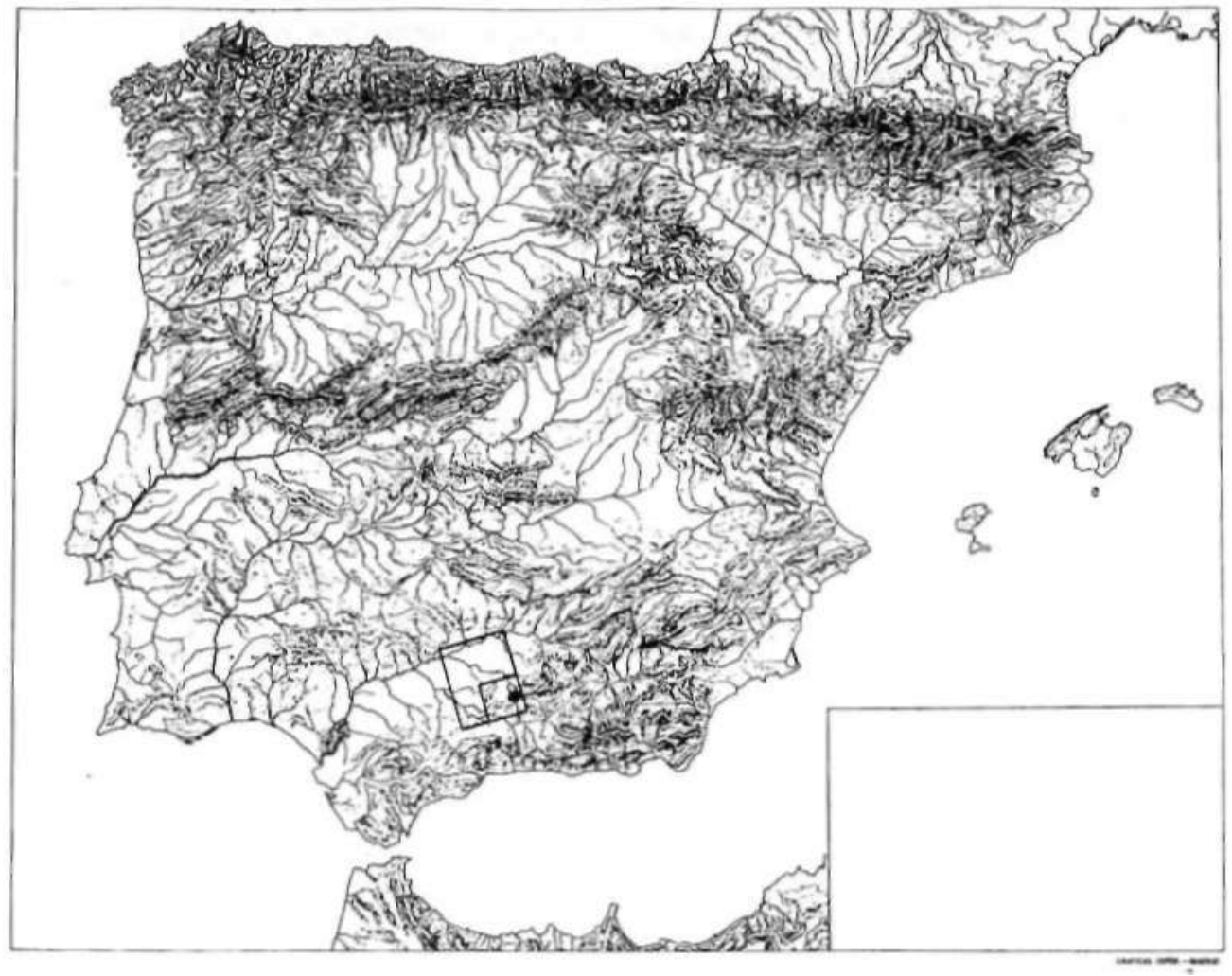

1. La Subbética en su contexto geográfico. 


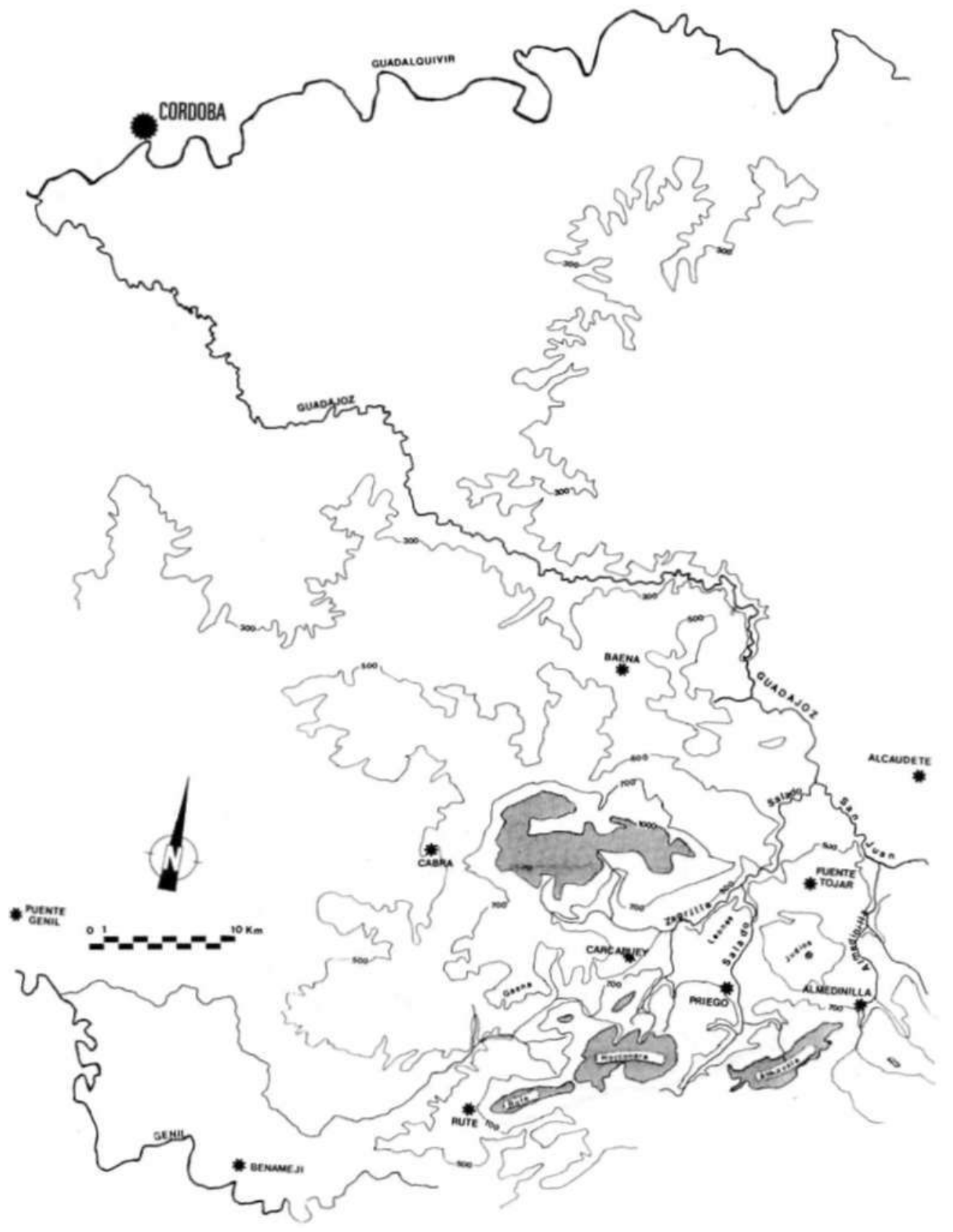

2. Situación de la región estudiada entre el Guadajoz y el Geni!, 


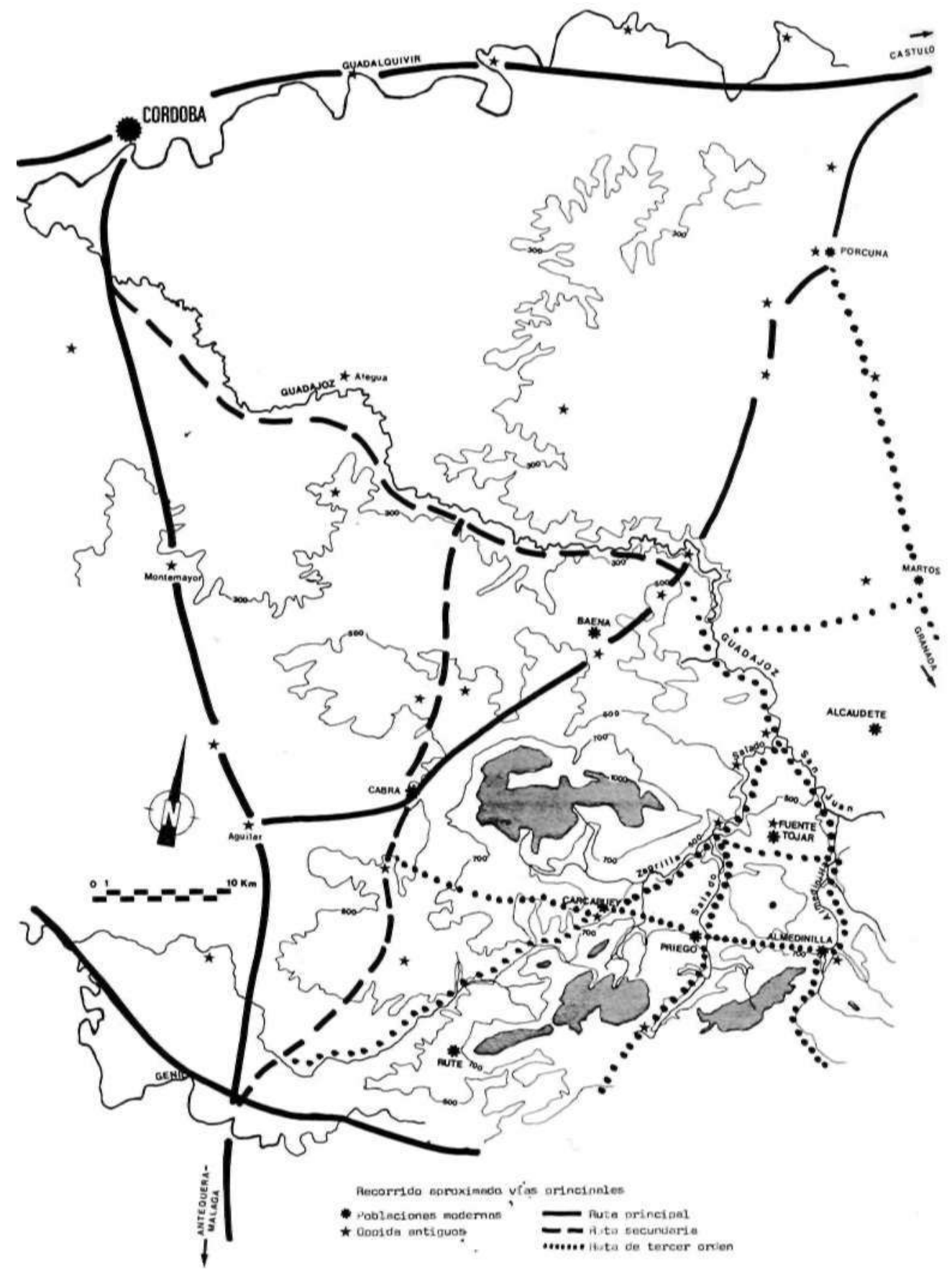

3. Recorrido de las principales rutas de comunicación. 


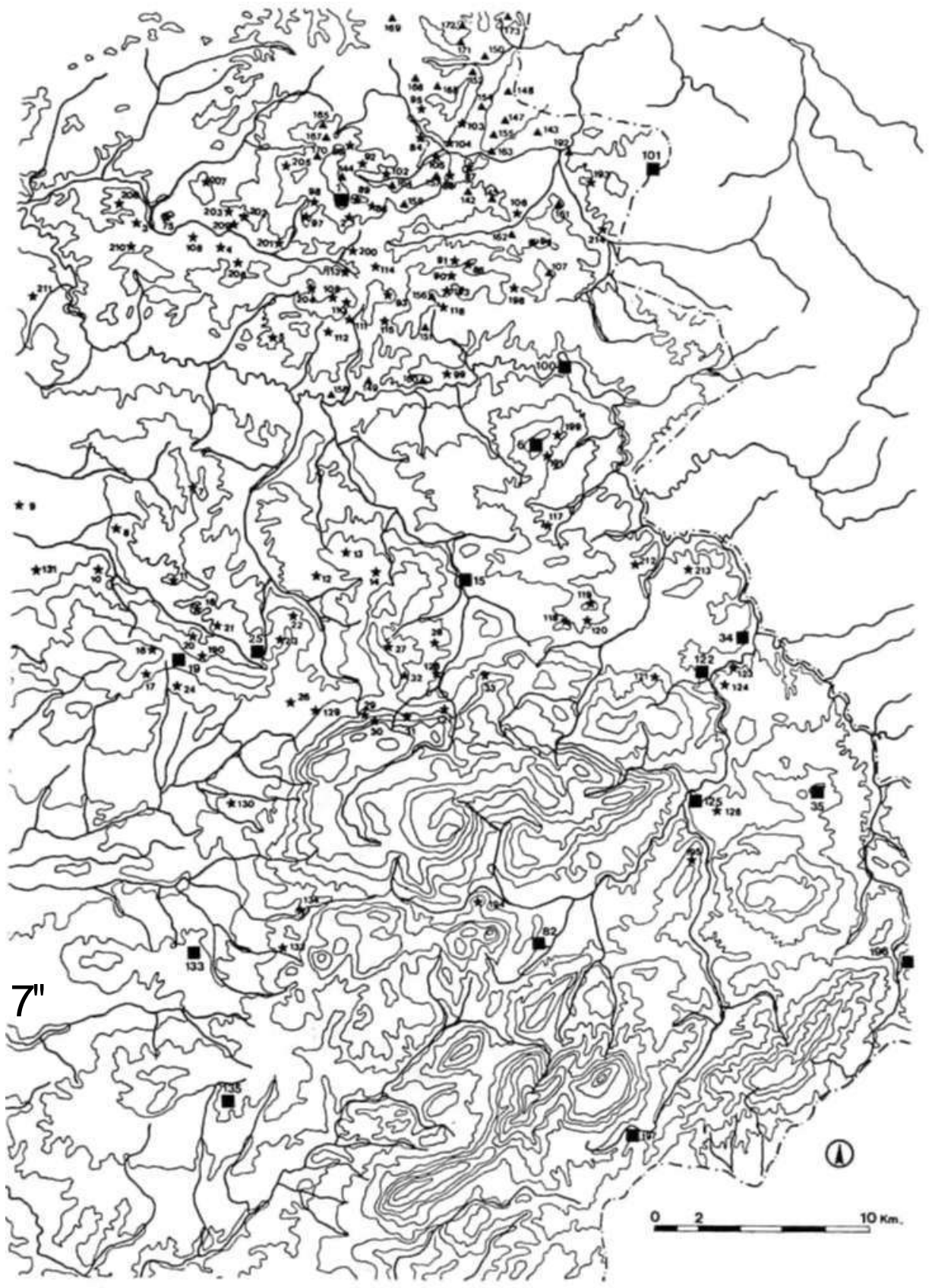

4. Distribución de yacimientos conocidos: vacío de investigación en la Subbética. 


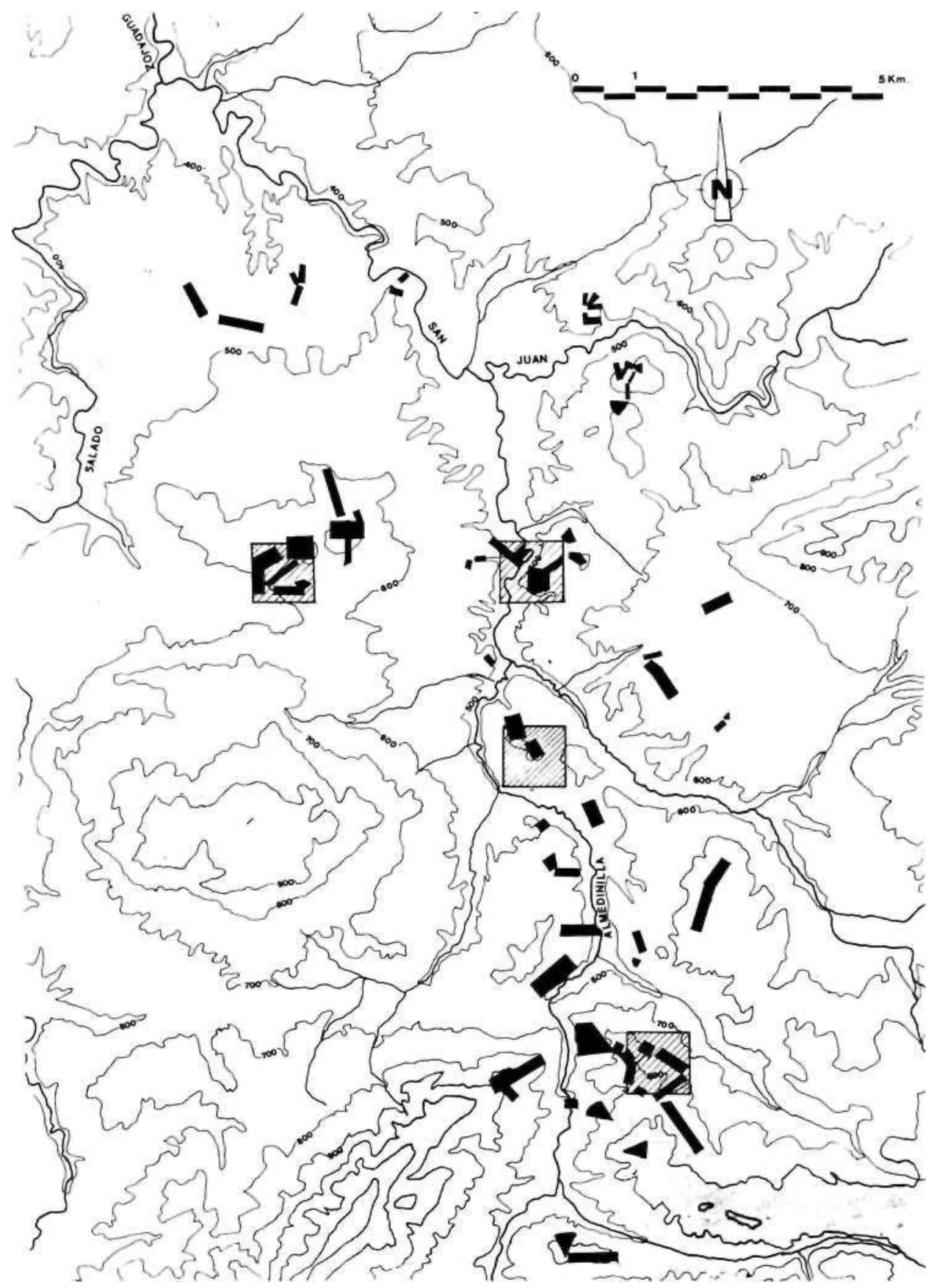

5. Área prospectada en 1989. Las cuadrículas rayadas corresponden a prospección aleatoria. 


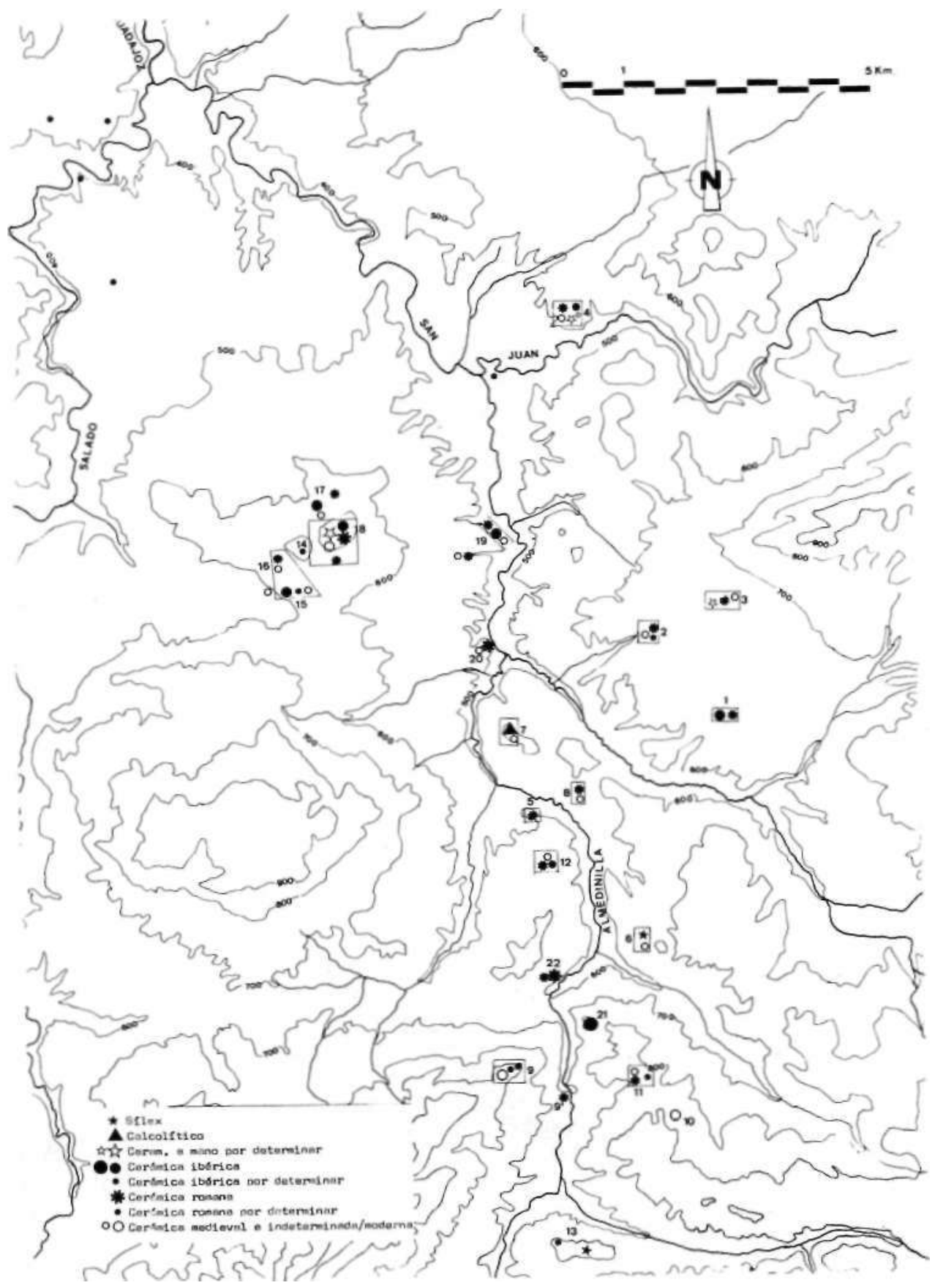

6. Resultados de la prospección de 1989.

1) Molino de Núñez. 2) Cerro Atalaya/Prado del Mármol. 3) Loma de la Cruz. 4) Cortijo Ramón . 5) Cota 601. 6) Cerro Alcalá. 7) Casüllarejo. 8) Los Ríos/El Llano. 9) Los Castillejos. 9bts) La Esperílla. 10) Barranco del Lobo. II) Kilómetro 4. 12) Cortijo de Albarillo. 13) Loma de Porras. 14) Las Cabezuelas. 15) Fuente Tójar. 16) Fuente Tójar 17) La Loma/Los Torvisca I es. 18) Cerro de las Cabezas. 19) Cortijo Caicena. 20) Cota 519, 21) Cerro de la Cruz/Necrópolis de Los Collados. 22) El Ruedo. 23) Los Torviscales. 

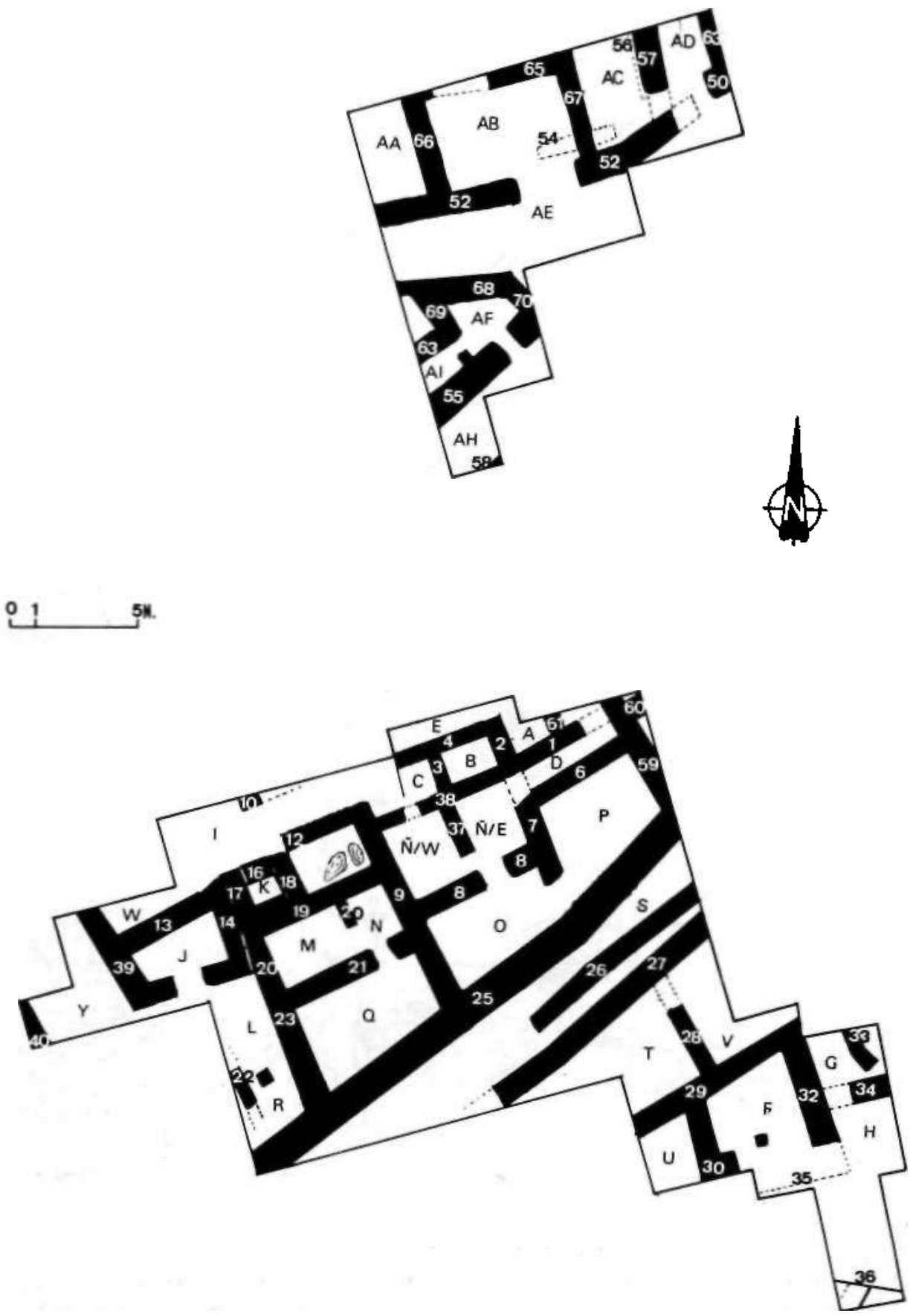

7. Croquis a escala de las estructuras documentadas en los sectores Central y Norte del poblado ibérico del Cerro de la Cruz.

--- Grupo de investigación P.A.I. HUM 236 | http://www.arqueocordoba.com/publ/anales.htm --- 